\title{
Evolution of the Flowering Pathways
}

\author{
Eva Lucas-Reina, M Isabel Ortiz-Marchena, Francisco J. Romero- \\ Campero, Myriam Calonje, José M. Romero, and Federico Valverde
}

\author{
Contents \\ 1 Introduction \\ 2 The Evolution of the Photoperiod Pathway \\ 2.1 Photoperiod Pathway in Vascular Plants \\ 2.2 Compared Evolution of Photoperiodic Signaling in Green Algae \\ and Land Plant \\ 3 Overcoming Temperature Changes \\ 3.1 Vernalization \\ 3.2 Ambient Temperature \\ 4 Nutrients Signaling to Flowering \\ 5 Flower Development \\ 5.1 Floral Identity Determination \\ 5.2 Floral Organ Identity Determination \\ 6 Conclusions \\ References
}

\begin{abstract}
Flowering plants are some of the most successful organisms on Earth, particularly those used in agriculture due to the widespread distribution produced by farming activities. The correct moment of the year to flower is a crucial decision as it strongly compromises the success of the progeny and is thus strictly controlled. Crops have been artificially selected to flower in those conditions better adapted for human production, and many genes related to flowering time are selected as targets for breeding programs. These characteristics reflect a complex regulatory pathway
\end{abstract}

Eva Lucas-Reina and M Isabel Ortiz-Marchena contributed equally to this work.

E. Lucas-Reina $\bullet$ M.I. Ortiz-Marchena • M. Calonje • J.M. Romero • F. Valverde $(\bowtie)$ Institute for Plant Biochemistry and Photosynthesis, Plant Development Unit, CSIC and Universidad de Sevilla, 49th Americo Vespucio Avenue, 41092 Seville, Spain e-mail: federico.valverde@ibvf.csic.es; http://www.ibvf.csic.es/en/molecular-basis-floweringphotoperiod-and-metabolism

F.J. Romero-Campero

Department of Computational Sciences and Artificial Intelligence, Research Group in Natural Computing, Universidad de Sevilla, Reina Mercedes Avenue, 41012 Seville, Spain 
that has to respond both to predictable and unexpected changes in the environment. This plasticity confers the flowering plants with a genetic toolkit to adapt to varied habitats and changing environmental conditions. Recent advances in massive acquisition of data from many different species belonging to the green eukaryotic lineage allow us to make an evolutionary approach to the main mechanisms that influence the floral transition and how flowers are formed in modern plants. This work will review some of these aspects from the floral transition to the floral organogenesis.

\section{Introduction}

The flowering transition is one of the most important developmental decisions that a plant has to take during its life cycle. An incorrect decision to flower has a strong negative influence on the capacity of the plant to transmit its genes to the next generation, and thus it is strictly regulated (Casal et al. 2004). This decision is strongly influenced by external and internal cues among which light, temperature and nutrient signals are probably the most influential (Amasino 2010). In order to understand the complex signaling events that promote or inhibit flowering, different pathways have been proposed and excellent reviews have been recently published (Smeekens et al. 2010; Huijser and Schmid 2011; Andrés and Coupland 2012; Song et al. 2012a, b, c), but they can all be directly or indirectly grouped into three groups (Fig. 1). The light pathway integrates those signals derived from the light quality, day length, or the circadian clock. The internal signals comprise those provided by hormones, nutrients (sugar, nitrogen compounds, etc.) and age. The temperature signals include the so-called autonomous pathway, the ambient temperature signals and the vernalization signals. These pathways will be described in more detail below.

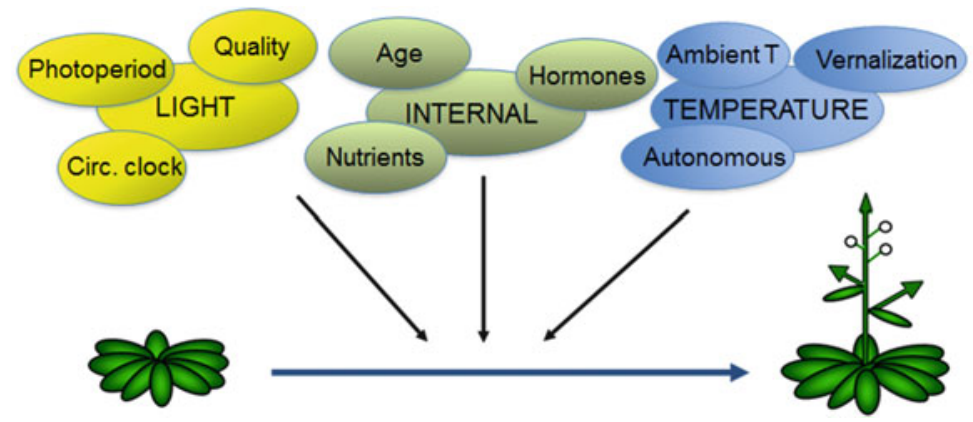

Fig. 1 Major pathways controlling the floral transition in Arabidopsis. Schematic representation of the three major cues that influence the floral transition in Arabidopsis. Light (yellow) includes photoperiodic, light quality, and circadian clock. Temperature (blue) includes vernalization, autonomous and ambient temperature signals. Internal (green) includes the effect of hormones, age, sugars and other metabolites (nutrients) 
Most of the plants will flower when one, or a combination of these signals, reaches the threshold that triggers the floral transition. This is coordinated by a network of genes that is highly conserved throughout evolution (Romero-Campero et al. 2013). In this work we will review recent knowledge about the gene networks that control the flowering pathways as well as floral organogenesis and how can we trace back this gene toolkit into the evolutionary story of plants. It will allow us to understand the origin of the flowering pathways and why they have reached such complexity in angiosperms. Inevitably, Arabidopsis thaliana will be the model to follow, as most of the flowering work has been done in this small brassica. Nevertheless, we will try to extrapolate this information into other plants representing different phylogenetic relationships and evolutionary steps within the green eukaryote lineage.

We will also review the process of floral organogenesis because it is chronologically and locally connected to the last stages of the floral transition within the shoot apical meristem (SAM). In this way, many of the late genes involved in the floral transition, including the floral integrators, control the early stages of floral formation. This assures the continuity in the signaling process necessary to achieve the successful step-by-step hierarchy of floral organogenesis.

\section{The Evolution of the Photoperiod Pathway}

The amount of incident light at a particular point on most of the Earth's surface changes throughout the year resulting in the different seasons, particularly in the middle half of the hemispheres where most of the human population is concentrated. Animals and plants have developed throughout their evolution molecular tools consisting in genes and signaling networks that transduce day length information (or photoperiod) into the regulation of key developmental and metabolic processes. This capacity is known as photoperiod response (Bradshaw and Holzapfel 2007).

\subsection{Photoperiod Pathway in Vascular Plants}

One of the most conserved day length responses among plants is the photoperiodic flowering pathway (Romero-Campero et al. 2013). CONSTANS (CO) is the central gene in this pathway and promotes flowering by inducing the expression of the florigen FLOWERING LOCUS T (FT) gene (Valverde 2011). Recent advances in genomics of vascular plants have allowed researchers to identify several genes that control flowering in species such as potato (Martínez-García et al. 2002), tomato (Corrales et al. 2014), sorghum (Murphy et al. 2011), rice (Yano et al. 2000) and Jatropha (Yang et al. 2011). Nevertheless, the long-day (LD) facultative plant 
Arabidopsis thaliana is the model organism where most studies have been performed (Amasino 2010).

In Arabidopsis, $C O$ and $F T$ expression are regulated by circadian and photoperiodic regulatory elements. In this sense, CYCLING DOF FACTOR (CDF) proteins are a group of four DOF transcription factors that bind to the $C O$ and FT promoters negatively regulating their expression (Imaizumi et al. 2005; Fornara et al. 2009; Song et al. 2012c). At the end of a LD, the blue light-dependent GI-FKF1 complex induces CDF degradation (Rubio and Deng 2007), allowing FLOWERING BHLHs (FBHs) to enhance $C O$ expression (Ito et al. 2012) and thereby $F T$ induction. Moreover, GIGANTEA (GI) is involved in $F T$ induction in a CO-independent way (Sawa and Kay 2011; Srikanth and Schmid 2011). CO expression is also regulated at the transcriptional level by the circadian clock whose core is constituted in Arabidopsis by the genes CIRCADIAN CLOCK ASSOCIATED 1 (CCA1), LATE ELONGATED HYPOCOTYL (LHY), and TIMING OF CAB EXPRESSION 1 (TOC1) (McClung 2014). Additionally, $C O$ is posttranslationally regulated by the $26 \mathrm{~S}$ proteasome due to the action of two E3 ubiquitin ligases with Ring Finger domains: CONSTITUTIVE MORPHOGENIC 1 (COP1) during the night and HIGH EXPRESSION OF OSMOTICALLY RESPONSIVE GENES 1 (HOS1) during the morning (Jang et al. 2008; Lazaro et al. 2012). Moreover, light has an important role in the regulation of $C O$ expression. The photoreceptor PHYTOCHROME B (PHYB) promotes CO degradation by red light, whereas CRYPTOCHROMES 1 and 2 (CRY1, CRY2) and PHYTOCHROME A (PHYA) promote its stability through a blue light signal (Valverde et al. 2004) specifically during the daylight period. This complex regulatory network determines that $C O$ mRNA coincides with a high stable protein level during the evening of a LD (external coincidence model) (Andrés and Coupland 2012) triggering the expression of the florigen FT gene. However, depending on its geographical location, plants have developed different regulatory mechanisms to anticipate photoperiod changes. For example, in short-day (SD) plants, such as rice (Oryza sativa), an FT homolog (HEADING DATE 3a, HD3A) is induced in SD by a CO homolog (HD1), whereas in LD HD1 behaves as a repressor of HD3A (Turck et al. 2008). Additionally, transgenic rice overexpressing $C D F$ homologs (OsDOF12) induces $H D 3 A$ expression only under LD conditions in a $H D l$-independent manner ( $\mathrm{Li}$ et al. 2009). In this species, GI promotes $H D l$ expression although it is yet unknown whether this regulation is direct or through a FKF1/CDF route similar to the one in Arabidopsis (Higgins et al. 2010).

The regulatory differences observed in vascular plants may reflect an evolutionary divergence produced by the needs to adapt to specific environmental conditions. This could explain the emergence of new regulatory genes involved in the same processes or the change in function of a specific gene. For example, in rice EARLY HEADING DATE 1 (EHD1), a B-type response regulator, induces HD3A transcription in SD conditions, independently of HD1 (Doi et al. 2004) and the GRAIN NUMBER, PLANT HEIGHT, and HEADING DATE 7 (GHD7) rice protein plays a key role in the photoperiod pathway (Xue et al. 2008). Nevertheless, no putative Arabidopsis orthologs of these genes have been identified so far. In potato, similar 
genes to those that control the floral transition also regulate other biological pathways such as tuberization. Both processes are finally controlled by two different $F T$-like paralogues, StSP3D that promotes flowering and StSP6A that regulates tuber formation (Navarro et al. 2011) in two separated transduction pathways. $S t S P 3 D$ and StSP6A respond to different photoperiod conditions involving the StGI-StFKF1 complex, StCDF, and StCO protein (Kloosterman et al. 2013). Interestingly, in neutral-day plants, where flowering time is not controlled by photoperiod, CDFs are involved in other biological processes not related to the photoperiod response. For example, in tomato, $S l C D F s$ are induced in response to abiotic stress conditions. Nevertheless, the SICDF heterologous expression in Arabidopsis delays flowering by reducing $C O$ and $F T$ transcript levels. This suggests that the ability of SICDFs to control the photoperiod response is conserved although it is not involved in the floral transition in these plants (Corrales et al. 2014).

Strikingly, flowering gene regulatory networks from a wide range of photosynthetic organisms share a large set of orthologs. This suggests that the photoperiodic gene regulatory network evolved very early in the green evolutionary linage constituting an ancestral network. The current photosynthetic organisms have then inherited this gene network from these common ancestors.

\subsection{Compared Evolution of Photoperiodic Signaling in Green Algae and Land Plants}

The latest results from our group and others (Serrano et al. 2009; Romero-Campero et al. 2013) have demonstrated an exclusive origin of the photoperiod response in algae of the Chlorophyceae class, which would have then evolved into the complex pathway of modern plants. In this section we will try to dissect the evolutionary processes involved.

\subsubsection{Homolog Genes in Chlamydomonas}

\section{CONSTANS Homolog}

Chlamydomonas reinhardtii is considered to be a living representative of the common ancestor that gave rise to the green eukaryotic lineage. The first gene related to the photoperiod pathway identified in the Chlamydomonas genome was a single-copy $\mathrm{CO}$ homolog, called $\mathrm{CrCO}$ (Serrano et al. 2009; Valverde 2011). $\mathrm{CrCO}$ was shown to be involved, among other mechanisms, in processes controlled by the circadian clock, such as starch synthesis and cell growth. Surprisingly, transgenic plants overexpressing $\mathrm{CrCO}$ under a constitutive or phloem-specific promoter, flowered earlier than WT and in a similar way to plants overexpressing the original $\mathrm{CO}$ gene. $\mathrm{CrCO}$ can, thus, complement $\mathrm{co}$ mutation. In contrast, $\mathrm{CO}$ like 1 (COLI) 
is unable to complement $c o$ mutation in spite of being evolutionarily more related to $\mathrm{CO}$ than $\mathrm{CrCO}$. Possibly, $\mathrm{CO}$ and $\mathrm{CrCO}$ share key structural similarities that are not reflected in the alignment of their sequences, which shows very low general amino acid identity. This constitutes an example of the limitations of using solely sequence similarity when detecting potential orthologs (Romero-Campero et al. 2013). Recently, evidence of the high relevance of the $\mathrm{CrCO}$ gene in the algae transcriptome has been suggested by gene co-expression analysis. It has been shown that the $\mathrm{CrCO}$ gene constitute a hub gene in a gene co-expression network constructed based on RNA-seq data from a wide range of relevant physiological conditions (Romero-Campero et al. 2013). A single-copy $\mathrm{CrCO}$ gene has evolved into numerous CONSTANS-LIKE (COLs) gene families in Physcomitrella (PpCOLs) and Arabidopsis (AtCOLs), establishing complex and robust networks with greater numbers of hub genes in both species (Romero-Campero et al. 2013). This diversification of the COL family in Physcomitrella and vascular plants and the high overlapping between their functions indicate that the different biological processes in which $\mathrm{CrCO}$, PpCOLs, and AtCOLs are involved are highly conserved across evolution (Romero-Campero et al. 2013). Additionally, COLs may have a wide repertoire of plant-specific light-dependent functions besides those already described (Valverde 2011) such as axillary ramification (Wang et al. 2013), bud dormancy (Böhlenius et al. 2006), and tuber growth (González-Schain et al. 2012).

\section{CDF Homologs}

The genome of Chlamydomonas contains another single-copy gene called $\mathrm{CrDOF}$ that seems to be part of the ancestral photoperiod pathway. $C r D O F$ evolution has produced a numerous gene family, the DOF transcription factors (TFs), following a similar evolutionary history as $\mathrm{CrCO}$. DOFs are specific TFs in vascular plants (Moreno-Risueño et al. 2007) and are not present in animal or fungi genomes. Specifically, Arabidopsis has 36 DOF proteins (Noguero et al. 2013) including the small family of four CDFs (Imaizumi et al. 2005; Fornara et al. 2009). In Chlamydomonas, CrDOF is regulated, in a similar way as CDFs in Arabidopsis, by the circadian clock and photoperiodic mechanisms. Additionally, like the CDFs, $\mathrm{CrDOF}$ controls $\mathrm{CrCO}$ transcription. Nevertheless, in contrast to the CDF function in Arabidopsis, $\mathrm{CrDOF}$ activates $\mathrm{CrCO}$ expression in Chlamydomonas by binding to its promoter. In addition, $\mathrm{CrDOF}$ controls important physiological processes in the algae exhibiting a surprisingly dual function, repressor or activator, depending on the day length. In this way $\mathrm{CrDOF}$ is able to induce cellular division by activating $\mathrm{CrCO}$ in $\mathrm{SD}$, whereas in $\mathrm{LD} \mathrm{CrDOF}$ represses the cell cycle progression to mitosis in a $\mathrm{CrCO}$-independent manner. CrDOF phenocopies $\mathrm{CDF}$ function in Arabidopsis so that transgenic plants expressing $C r D O F$ under different tissuespecific promoters delay flowering by suppressing $C O$ and $F T$ expression. Finally, RNA-seq data analysis revealed an apparent functional overlap between $\mathrm{CrDOF}$ and DOF proteins. These results reflect again how the functions of proteins involved in photoperiodic responses are extremely conserved across evolution. 
The diversification and subsequent acquisition of new regulatory domains by CrDOF (which has only a DOF domain and nuclear localization signal) to vascular plant DOF factors could explain the new regulatory processes in which CDFs and other DOF proteins are involved (Lucas-Reina et al. 2015).

\subsubsection{Putative Homologs}

Several putative Chlamydomonas orthologs of Arabidopsis genes involved in the photoperiod response have been identified using non-curated bioinformatic methods such as the BBH (bidirectional best hit) method (Table 1). Their involvement in the photoperiod response in Chlamydomonas and their interactions with $\mathrm{CrCO}$ and $\mathrm{CrDOF}$ are yet to be validated experimentally. Here we analyzed the conservation of the co-expression patterns among these genes by comparing them to the co-expression patterns of homologs from Arabidopsis (Fig. 2).

\section{Circadian Clock Genes}

Approximately 30 putative genes have been identified in Chlamydomonas that are involved in the control of circadian processes. These genes are called RHYTHM OF CHLOROPLAST (ROC). Some of the codified proteins are specific from algae; others present conserved domains with plant circadian clock proteins (Matsuo and Ishiura 2011). Strikingly, other ROCs present domains similar to those found only in animal proteins involved in circadian rhythm control (Schulze et al. 2010). Specifically, ROC40 has a MYB domain similar to CCA1 and LHY proteins and ROC66, which presents B-box and CCT domains similar to CO, to COL1, involved in circadian clock (Ledger et al. 2001) and COL9 (Matsuo and Ishiura 2011). ROC66 CCT domain is also similar to the CCT domain from Arabidopsis TOC1 (Matsuo and Ishiura 2011). Besides the sequence similarity that ROC40 and ROC66 show with CCA1/LHY and TOC1, these two Chlamydomonas genes also exhibit similar co-expression patterns as their putative Arabidopsis orthologs. CCA1/LHY and $T O C 1$ present a negative co-expression pattern in Arabidopsis, which seems to be conserved in Chlamydomonas, as CrLHY and CrTOCl show a negative co-expression pattern (Fig. 2).

The conservation of the circadian clock core genes, CCA1/LHY and TOC1, has also been found in the green algae Ostreococcus tauri, although in this case, their expression patterns differ from those in the Arabidopsis genes (Bouget et al. 2014).

\section{Photoreceptors}

Light perception in plants is carried out by a set of different photoreceptors. One of them is the phototropin (PHOT) involved in physiological processes like phototropism and stomatal opening. On the other hand, cryptochromes (CRYs) and 
Table 1 Genes involved in the photoperiod response in Arabidopsis and Chlamydomonas

\begin{tabular}{l|l|l}
\hline Gene name & Arabidopsis thaliana & Chlamydomonas reinhardtii \\
\hline$C O$ & At5g15840 & $\mathrm{g} 6302$ \\
\hline COL1 & At5g15850 & $\mathrm{g} 6302$ \\
\hline$F T$ & At1g65480 & Not identified \\
\hline$C D F 1$ & At5g62430 & Cre12.g521150 \\
\hline$C D F 3$ & At3g47500 & Cre12.g521150 \\
\hline FBH1 & At1g35460 & Cre14.g620850 \\
\hline FBH4 & At2g42280 & Cre14.g620850 \\
\hline ZTL & At5g57360 & Cre12.g518800 \\
\hline FKF1 & At1g68050 & Cre12.g518800 \\
\hline GI & At1g22770 & Not identified \\
\hline TOC1 & At5g61380 & g16738 \\
\hline LHY & At1g01060 & Cre06.g275350 \\
\hline$C C A 1$ & At2g46830 & Cre06.g275350 \\
\hline$C R Y 1$ & At4g08920 & Cre06.g295200 \\
\hline$C R Y 2$ & At1g04400 & Not identified \\
\hline$H O S 1$ & At2g39810 & g16152 \\
\hline$C O P 1$ & At2g32950 & Cre02.g098100 \\
\hline & &
\end{tabular}

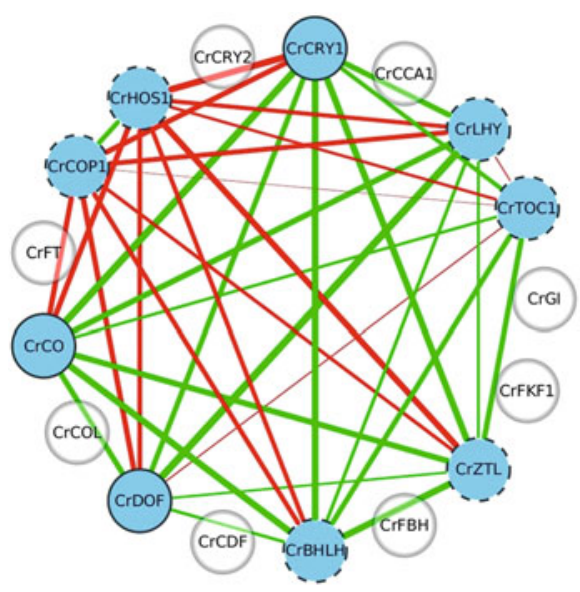

Chlamydomonas

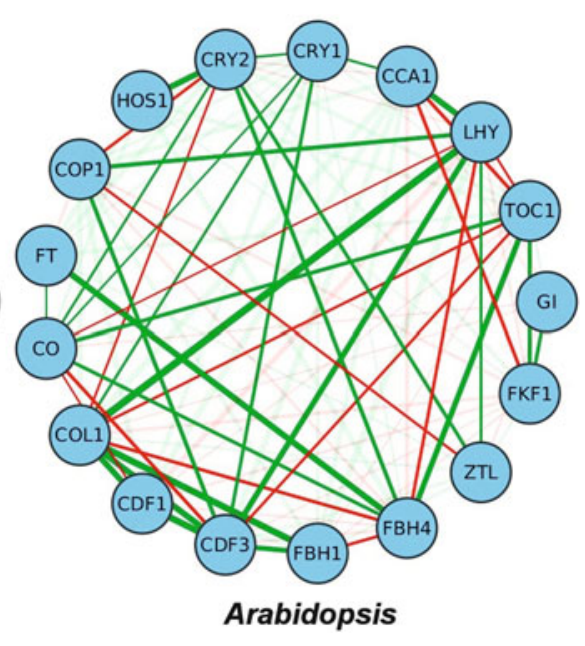

Fig. 2 Co-expression patterns between genes involved in the photoperiod response in Chlamydomonas and Arabidopsis. The figure represents co-expression relationships (green, positive; red, negative) between the genes (blue circles) involved in the photoperiod response in Chlamydomonas and Arabidopsis. A conserved co-expression pattern is apparent together with processes of gene duplication as well as specific network rewiring: the circadian clock genes $C C A 1 / L H Y$ and $T O C l$ are negatively co-expressed in both organisms. Processes of gene duplication have produced Arabidopsis genes such as $C D F 1$ and $C D F 3$ from the $C r D O F$, or $C O$ and $\mathrm{COL1}$ from $\mathrm{CrCO}$, from Chlamydomonas. Nevertheless, while the positive co-expression between $\mathrm{CrDOF}$ and $\mathrm{CrCO}$ in Chlamydomonas has been conserved in the Arabidopsis CDF1 and COL1, the co-expression between $C D F 1$ and $C O$ is negative in Arabidopsis 
phytochromes (PHYs) are involved in morphogenetic, photoperiodic, and circadian mechanisms like flowering.

PHOTs are the principal sensory molecules for light-dependent life cycle control in Chlamydomonas and other green algae like Ostreococcus tauri. PHOT is a modular protein formed by a light, oxygen, or voltage (LOV) domain, similar to that of the protein family ZTL-FKF1-LKP2, in the amino terminal part of the protein, followed by a carboxy-terminal histidine kinase (HK) domain (LOV-HK). In contrast to PHOTs that are specific of the green linage, the LOV-HK domain is related to the large family of LOV-HK domains found in different kinds of prokaryotes (Djouani-Tahri et al. 2011).

Chlamydomonas PHOTOLIASE HOMOLOG $1(\mathrm{CPH})$ encodes a protein with a significant sequence similarity with two plant-specific CRYs (CRY1 and CRY2) involved in the photoperiodic pathway. CPH1 levels are controlled by blue and red light, which induce the instability of the protein (Reisdorph and Small 2004). In this text we refer to $C P H I$ as $C r C R Y 1$. Specific co-expression patterns such as the positive co-expression between $\mathrm{CrCRYl}$ and $\mathrm{CrCO}$ seem to be conserved in Arabidopsis between the genes $C R Y I$ and $C O$.

Moreover, in Chlamydomonas aCRY (animallike CRY) and DASH-CRYs (Drosophila, Arabidopsis, Synechocystis, and Homo-like CRY) (Beel et al. 2013) have been described, indicating that the evolutionary origin of cryptochromes precedes the green eukaryote lineage separation.

PHY-related proteins are a conserved multidomain protein found in bacteria (including cyanobacteria), fungi, and many eukaryotic algae like prasinophytes (green algae), heterokonts (diatoms and brown algae), and glaucophytes. All PHYs use bilin chromophores to sense light. Nevertheless, in algae unlike plants, PHY can sense orange, green, and blue light. In Chlamydomonas, in spite of retaining the ability to synthesize bilin, no protein with a significant sequence similarity with any PHY has been identified (Rockwell et al. 2014).

\section{Flowering bHLH Homologs}

FBH proteins are part of the large family of eukaryotic basic helix-loop-helix (bHLH)-type transcription factors. bHLHs present a wide diversity and a great number of genes in plant and mosses; in contrast, there is a small family in green and red algae. Particularly, in the Chlamydomonas genome only four bHLH genes have been identified (Riaño-Pachón et al. 2008; Carretero-Paulet et al. 2010; Pires and Dolan 2010). Only one of these genes presents significant similarity with bHLH genes present in higher plants such as Arabidopsis. We will refer to this gene as CrbHLH. The rest of $b H L H$ genes seem to be specific of the Chlorophyceae. Additionally, $\mathrm{Cr} b H \mathrm{H} H$ exhibits positive co-expression patterns with genes such as $\mathrm{CrCO}$ and $\mathrm{CrCRYl}$. These patterns are conserved in Arabidopsis between the genes $\mathrm{FBH} 4, \mathrm{CO}$, and $\mathrm{CRY} 2$. 
Constitutive Photomorphogenic 1 and High Expression of Osmotically

Responsive Genes 1

COP1 and HOS1 are members of the E3 ubiquitin ligase family with a Ring-finger domain. Up to now, COP1 has been identified in plants and red algae like Cyanidioschyzon merolae, whereas HOS1 has been found only in plants (RiañoPachón et al. 2008). Nevertheless, recent updates of the web portal for plant comparative genomics Phytozome include potential Chlamydomonas orthologs for both genes. These genes have been identified using automatic bioinformatic tools such as the bidirectional best hit method. The conservation of certain co-expression patterns involving these genes supports their consideration as potential orthologs.

\subsubsection{Unidentified Genes in Algae}

Up to now, no GI and FT homologs have been identified in any alga species (Corellou et al. 2009; Piñeiro and Jarillo 2013). Therefore, these proteins may have been acquired later in evolution. In fact, the first evidence of a GI binding site in a DOF protein has been found in Physcomitrella patens (LucasReina et al. 2015).

\section{Overcoming Temperature Changes}

Temperature is a key environmental variable that exerts a strong influence on the floral transition. Plants adapted to temperate climates are exposed to annual cold cycles but also to fluctuations of temperature within the different seasons; consequently, they need to differentiate the timing and interval of cold to bloom at the right time in order to increase their reproductive success (Preston and Sandve 2013). Many species from temperate climates require a prolonged exposure to cold in order to become competent to flower (Chouard 1960); this period is known as vernalization. The requirement for vernalization delays reproductive growth during winter minimizing the risk of frost damage to cold-sensitive reproductive organs and ensures that reproductive development and seed production occur in spring and summer (Amasino 2004, 2010; Kim et al. 2009). In addition, most plants in temperate regions face fluctuations in temperatures within the ambient range (above $10{ }^{\circ} \mathrm{C}$ ) and should be able to perceive and integrate these signals (Samach and Wigge 2005). These non-stressful temperatures have been shown to strongly influence flowering time, causing either a delay or an acceleration of flowering (Westerman and Lawrence 1970; Blazquez et al. 2003). Interestingly, recent reports indicate that the ambient temperature changes are sensed and transduced differently than extreme temperature changes. Here, we will discuss the current knowledge at the molecular level on the mechanisms that control flowering 
time in response to cold and non-stressful temperatures in different plant species, which will help us to understand the evolution of alternative mechanisms.

\subsection{Vernalization}

Vernalization responsiveness has evolved independently on multiple occasions (Greenup et al. 2011; Oliver et al. 2013); accordingly, genes controlling vernalization have been identified in different plant lineages (Danyluk et al. 1998; Michaels and Amasino 1999; Sheldon et al. 1999; Izawa et al. 2003; Trevaskis et al. 2003; Pin et al. 2010).

In A. thaliana, two genes, FRIGIDA (FRI) and FLOWERING LOCUS C (FLC), are the major natural determinants for the vernalization response (Shindo et al. 2005; Lovell et al. 2013; Li et al. 2014). The role of the single-copy gene $F R I$ is to activate the expression of $F L C$, which is a MADS-box-type repressor that prevents flowering. Downregulation of $F L C$ expression requires a long exposure to cold (Michaels and Amasino 1999). FRI induces FLC expression through direct interaction with the nuclear cap-binding complex (Geraldo et al. 2009; Crevillen and Dean 2011). In addition, recent studies have demonstrated that FRI-mediated upregulation of $F L C$ is associated with epigenetic modifications, primarily to a marked increase in the histone $\mathrm{H} 3$ lysine 4 trimethylation ( $\mathrm{H} 3 \mathrm{~K} 4 \mathrm{me} 3)$ pattern (Bastow et al. 2004; Sung and Amasino 2004a; Finnegan and Dennis 2007). The repression of FLC by cold involves different mechanisms (Song et al. 2012a). Briefly, an antisense transcript called COOLAIR is upregulated after 2-3 weeks of cold leading to the downregulation of FLC transcription (Swiezewski et al. 2009). In addition, a sense noncoding RNA (ncRNA) transcript, called COLDAIR (Heo and Sung 2011), is also induced by cold but later than COOLAIR. COLDAIR recruits the polycomb group complex VRN-PRC2 to FLC chromatin to mediate gene silencing through the incorporation of histone 3 lysine 27 trimethyl (H3K27me3) marks (De Lucia et al. 2008; Heo and Sung 2011; Crevillen et al. 2013; Kim and Sung 2014). Components of VRN-PRC2 complex are the VEFS domain containing protein VERNALIZATION 2 (VRN2), the SET-domain catalytic subunit CURLY LEAF (CLF) or SWINGER (SWN), FERTILIZATIONINDEPENDENT ENDOSPERM (FIE), and MULTICOPY SUPRESSOR OF IRA1 (MSI1) (Kim and Sung 2014). Additional components of the VRN-PRC2-mediated repression are the plant-specific B3 DNA-binding protein VRN1, and the plant homeodomain (PHD) motif containing proteins VERNALIZATION INSENSITIVE 3 (VIN3), VIN3-LIKE 1 (VIL1), and VERNALIZATION 5 (VRN5), which are nonredundantly necessary for the repression (Levy et al. 2002; Sung and Amasino 2004b; Sung et al. 2006; Greb et al. 2007). VRN1, VRN2, and VIL1/ VRN5 are constitutively expressed regardless of vernalization. In contrast, VIN3 is only induced when plants are kept under prolonged periods of cold temperature and quickly decreases when plants are returned to warm growth temperatures. Therefore, VIN3 is a cold-specific component of the vernalization pathway in A. thaliana 
Table 2 Arabidopsis vernalization orthologs in monocots and brassicas

\begin{tabular}{l|l|l|l|l}
\hline $\begin{array}{l}\text { Arabidopsis } \\
\text { thaliana }\end{array}$ & $\begin{array}{l}\text { T. aestivum } \\
\text { H. vulgare }\end{array}$ & Brassica oleracea & $\begin{array}{l}\text { Beta } \\
\text { vulgaris }\end{array}$ & $\begin{array}{l}\text { Arabis } \\
\text { alpina }\end{array}$ \\
\hline AP1 & VRN1 & AP1 1 & - & - \\
\hline FLC & $\begin{array}{l}\text { VRN2 (COL } \\
\text { family) }\end{array}$ & $\begin{array}{l}\text { FLC1,FLC2,FLC3,FLC4, } \\
\text { FLC5 }\end{array}$ & FL1 & PEP1 \\
\hline$F T$ & VRN3 & $F T$ & FT1,FT2 & - \\
\hline
\end{tabular}

(Sung and Amasino 2004b; Kim and Sung 2013, 2014). Nevertheless, the promotion of flowering by vernalization is not exclusively caused by the repression of $F L C$, as plants with a null allele of $F L C$ maintain some response to vernalization (Michaels and Amasino 2001), suggesting that other genes are involved. The MADS AFFECTING FLOWERING 1-5 (MAF1-5), which are FLC homologs (Ratcliffe et al. 2001, 2003; Scortecci et al. 2001), have been proposed to play a role in the vernalization response; however, their molecular mechanism of action is unknown (Ratcliffe et al. 2003).

Interestingly, several data showed that the extensive allelic heterogeneity at both $F R I$ and FLC can account for a major fraction of the natural variation in vernalization rate in different A. thaliana ecotypes (Johanson et al. 2000; Gazzani et al. 2003; Shindo et al. 2005; Geraldo et al. 2009; Li et al. 2014). FRI-like genes with a similar function to A. thaliana FRI have been identified in many species, such as Brassica oleracea, A. lyrata, Capsella sp., Thellungiella halophila, Medicago truncatula, Lotus japonicus, Vitis vinifera, Populus balsamífera, and Oryza sativa (Goff et al. 2002; Fang et al. 2008; Kuittinen et al. 2008; Slotte et al. 2008; Risk et al. 2010; Keller et al. 2011; Irwin et al. 2012). Variations in the vernalization responsiveness have been also shown in many of these species (Irwin et al. 2012), suggesting its functional conservation throughout plant evolution. Conversely, FLC-like genes as temperature-controlled floral repressors have been identified only in Arabidopsis, Brassica, Arabis, sugar beet (Beta vulgaris), and Petunia (Michaels and Amasino 1999; Tadege et al. 2001; Schranz et al. 2002; Vandenbussche et al. 2003; Reeves et al. 2007; Wang et al. 2009) (Table 2).

Arabis alpina, a perennial relative of Arabidopsis, resumes vegetative growth in fall and repeatedly undergoes vernalization. An FLC ortholog [PERPETUAL FLOWERING 1 (PEPI)] acts as a major floral repressor in Arabis (Wang et al. 2009). PEPI is repressed by vernalizing cold and thus allows plants to bloom. Unlike Arabidopsis, PEPI is reactivated when plants are returned to warm growth temperature (Kim and Sung 2014). In sugar beet, a pair of $F T$ homologs ( $B v F T 1$ and $B v F T 2$ ) acts antagonistically in the floral transition. BvFT1 acts as a floral repressor whereas $B v F T 2$ promotes flowering (Pin et al. 2010). Vernalization results in downregulation of $B v F T 1$. Vernalization-induced repression of BvFT1 is stably maintained even after plants are returned to warm growth temperatures, indicating that $B v F T 1$ functions similarly to $F L C$. Vernalization requirement in sugar beet is mainly conferred by a dominant allele named $B v B T C 1$ through its regulation of BvFT1 and BvFT2 (Pin et al. 2010). Annual 
sugar beet plants with a dominant $B v B T C 1$ allele do not need vernalization for early flowering. In contrast, biennial sugar beet plants carry a partial loss-of-function allele of Bvbtcl. Bvbtcl is not significantly induced even under LD without vernalization treatment. $B v b t c l$ allele can be gradually activated by vernalization treatment to the level sufficient to repress $B v F T 1$ and activate $B v F T 2$ (Kim and Sung 2014).

Recent studies have revealed that the vernalization pathway emerged from a convergent evolution in dicots and monocots (Amasino and Michaels 2010; Greenup et al. 2011; Ream et al. 2012). In cereals, like wheat or barley, flowering is accelerated by vernalization (by a gene resembling CONSTANS), as the change in photoperiod in winter time is a stronger floral determinant than temperature (Dubcovsky et al. 2006). In fact, in rice the flowering pathway is regulated mainly by photoperiod, as it does not present a vernalization requirement (Song et al. 2012b).

Genetic analyses in the temperate cereals wheat and barley have shown that three genes determine the vernalization responsiveness: VRN1, VRN2, and VRN3 (Pugsley 1971; Yan et al. 2006). They are, nevertheless, different genes than those with the same name in A. thaliana (Table 2). VRNI encodes an APETALAl-like MADS-box transcription factor with high similarity to the A. thaliana meristem identity genes APETALAI (API), CAULIFLOWER (CAL), and FRUITFULL $(F U L)$. VRN1 is induced after vernalization (Trevaskis et al. 2003; Yan et al. 2003; Oliver et al. 2009; Xiao et al. 2014). VRN2 is the A. thaliana FLC functional analogue, although it belongs to the COL gene family (Yan et al. 2004; Higgins et al. 2010). VRN2 is a floral repressor that represses VRN3, the ortholog of A. thaliana FT, under LD conditions. VRN2 expression is downregulated after vernalization (Trevaskis et al. 2007). Hence, after vernalization the expression of VRN1 increases, while VRN2 expression decreases (Yan et al. 2004). On the other hand, VRN3 induces VRN1 in LD conditions (Wigge et al. 2005; Yan et al. 2006). The three genes thus form a regulatory loop. Interestingly, Arabidopsis and wheat have different genes, FLC and VRN2, with the same function. However, vernalization in wheat does not result in significant changes in histone modifications at $V R N 2$, suggesting that changes of chromatin structure at VRN2 locus do not occur. Conversely, induction of VRN1 in barley is epigenetic; however, the epigenetic changes are the opposite of those in FLC. In VRNI there is a decrease in $\mathrm{H} 3 \mathrm{~K} 27 \mathrm{me} 3$, the mark of a transcriptionally inactive gene, and an increase in $\mathrm{H} 3 \mathrm{~K} 4 \mathrm{me} 3$, a mark of an active gene. Activation of VRN1 is quantitative, with longer cold treatments inducing higher levels of expression (Distelfeld et al. 2009; Oliver et al. 2009, 2013). On the other hand, Brachypodium spp. have an ortholog of VRN1 similar to both wheat and barley that promotes flowering; however, VRN2 is not conserved in this plant (Ream et al. 2014). Surprisingly, a recent report suggested that an FLC-like gene is present in monocots, although its function remains to be investigated (Ruelens et al. 2013).

The epigenetic memory of vernalization is maintained by the PcG proteins in Arabidopsis. PcG proteins evolved early in evolution, probably in the common ancestor of animals and plants. As evidenced from the variable copy number of 
homologs in plants, diversification of PRC2 subunits occurred only recently in evolution, mostly after the split of monocots and dicots. There are three VEFS domain containing proteins in A. thaliana, EMBRYONIC FLOWER2 (EMF2), VRN2, and FERTILIZATION-INDEPENDENT SEED 2 (FIS2), that bestow partially specialized functions on the corresponding PRC2 complexes. In general, there are several copies of $V E F$ genes in dicots as well as in monocots; however, the absence of a VRN2 ortholog in other species (Luo et al. 2009) suggests that PcG function in the regulation of vernalization response evolved especially in Brassicaceae (Derkacheva and Hennig 2014). Nevertheless, it might be possible that a different VEFS gene participates in the vernalization response in other species. Interestingly, three VIL homologs have been identified in the einkorn wheat (Triticum monococcum L.) (Fu et al. 2007) and in its wild relative Aegilops tauschii (Koyama et al. 2012). Of the three AetVIL genes, AetVIL2 was upregulated after 1 week of low-temperature treatment, and its expression pattern was distinct for winter and spring habit accessions. These observations strongly suggest that AetVIL2 is associated with the vernalization-responsive pathway in A. tauschii (Koyama et al. 2012).

\subsection{Ambient Temperature}

Recent works in Arabidopsis have shed some light in the molecular mechanisms underlying the effect of ambient temperatures on flowering time (Verhage et al. 2014). Warm temperature induces flowering in Arabidopsis by upregulation of FT expression (Halliday et al. 2003; Balasubramanian and Weigel 2006). The acceleration of flowering in response to high temperature requires the activity of PHYTOCHROME INTERACTING FACTOR4 (PIF4) that directly binds to the FT promoter in a temperature-dependent manner (Kumar et al. 2012). The PIF4 binding site in the $F T$ promoter is occupied by the histone H2A variant H2A.Z, inhibiting its transcription. FT expression increases as H2A.Z-containing nucleosomes are evicted in response to high temperatures (Kumar and Wigge 2010; Kumar et al. 2012). Accordingly, mutations of ACTIN-RELATED PROTEIN6 (ARP6) that compromise H2A.Z occupancy cause the warm temperature transcriptome to be constitutively expressed (Kumar and Wigge 2010). However, other plant species respond in an opposite manner to an increase in the ambient temperature or stay largely independent. Therefore, it is important to determine the evolution of these genes and mechanisms to understand plant response to temperature fluctuations. Recent analysis of the genome of Brassica rapa revealed the presence of three orthologs of PIF4 (Song et al. 2014), while two close orthologs of PIF4 and PIF5 exist in rice (Oryza sativa) (Nakamura et al. 2007), indicating that PIF4 might be conserved. However, whether there is also a functional conservation cannot be inferred from these genomic data. On the other hand, histone variant $\mathrm{H} 2 \mathrm{~A} . \mathrm{Z}$ is conserved among eukaryotes and has been proposed to mediate warm temperature signals in budding yeast (Saccharomyces cerevisiae) as in Arabidopsis 
(Kumar and Wigge 2010). Therefore, concerning the conservation of the H2A.ZPIF4 mechanism, H2A.Z is likely not to be the variable factor. As H2A.Z depletion functions as an enabler, rather than an activator of the higher temperature response, transcription factors can differentially regulate gene expression when shifted to a higher temperature. The fact that H2A.Z depletion only provides access to their targets might explain why plants have evolved a different response to increasing ambient temperatures.

Conversely, the MADS-domain proteins FLM and SVP (SHORT VEGETATIVE PHASE) are involved in the suppression of flowering at low ambient temperatures in Arabidopsis (Hartmann et al. 2000; Ratcliffe et al. 2001; Scortecci et al. 2001; Werner et al. 2005; Balasubramanian and Weigel 2006; Lee et al. 2007, 2013; Pose et al. 2013). FLM (also known as $M A F 1$ ) is a transcription factor that belongs to the $F L C$ clade. Interestingly, $F L M$ is alternatively spliced under different ambient temperatures. The two main splice forms function antagonistically through interaction with SVP (Balasubramanian and Weigel 2006; Pose et al. 2013). Low ambient temperatures favor the production of the $F L M \beta$ splice form, whereas more of the $F L M \delta$ splice form is produced at high ambient temperatures. Both FLM $\beta$ and FLM $\delta$ interact with SVP. FLM $\beta-S V P$ complex binds to DNA as a repressor of flowering. However, the interaction between SVP and FLM $\delta$ results in a functionally ineffective complex, leading to the formation of less repressive FLM $\beta-S V P$ complexes. In addition, FLM $\beta-S V P$ complex is regulated through protein stability of SVP (Lee et al. 2013). SVP protein becomes gradually less abundant as temperature increases from 16 to $27{ }^{\circ} \mathrm{C}$. Decrease in SVP protein leads to a lower abundance of the repressing FLM $\beta-S V P$ complex. Therefore, the regulation of FLM isoforms together with the regulation of SVP protein abundance contributes to repress flowering under low ambient temperatures. Interestingly, all FLC clade members (FLM/MAF1, MAF2, MAF3, MAF4, and MAF5) are alternatively spliced. However, it seems that $M A F 2-M A F 4$ have evolved different temperature sensitivities (Verhage et al. 2014).

Little is known about the implication of these MADS-box genes in the regulation of flowering time in response to ambient temperature in other species. FLC-like genes have been mainly identified as temperature-controlled floral repressors in Arabidopsis, Brassica, and sugar beet (Beta vulgaris) (Michaels and Amasino 1999; Tadege et al. 2001; Schranz et al. 2002; Reeves et al. 2007). Many MADSbox genes have conserved functions across the flowering plants; however, some have acquired novel functions in specific species during evolution. Particularly, the evolution of MADS-box gene subfamilies that control the vegetative-to-floral transition appears to be highly dynamic and linked to the enormous complexity of life history strategies in flowering plants ranging from ephemeral annuals to long-lived trees (Smaczniak et al. 2012a). Future research in other plant species will help to determine whether the orthologs of these or other MADS-box genes have been recruited to this function in other species.

Finally, miR156 and miR172 have been also proposed to regulate floral timing by ambient temperature. Besides timing of the juvenile phase, these two miRNAs have a role in the timing of the phase change from vegetative to reproductive 
(Aukerman and Sakai 2003; Wu and Poethig 2006; Verhage et al. 2014). Interestingly, it has been recently shown that miR156-SQUAMOSA PROMOTER BINDING PROTEIN-LIKE 3 (SPL3) module directly regulates FT expression in the leaf to control ambient temperature response to flowering. Overexpression of miR156 leads to more delayed flowering at a lower ambient temperature $\left(16^{\circ} \mathrm{C}\right)$, which has been associated with downregulation of FT and FUL expression. Among miR156 target genes, $S P L 3 \mathrm{mRNA}$ levels are significantly reduced at $16^{\circ} \mathrm{C}$. Overexpression of miR156-resistant SPL3 causes early flowering, regardless of the ambient temperature. Furthermore, SPL3 protein directly binds to GTAC motifs within the FT promoter. These data suggest that the interaction between the miR156-SPL3 module and FT is part of the regulatory mechanism controlling flowering time in response to ambient temperature (Kim et al. 2012). Conversely, a higher miR172 expression was observed at $23{ }^{\circ} \mathrm{C}$ than at $16{ }^{\circ} \mathrm{C}$ (Lee et al. 2010). Both miR 156 and miR172 belong to a subset of evolutionary conserved miRNAs that are present throughout the angiosperms (Axtell and Bowman 2008; Cuperus et al. 2011). Results obtained in different dicots and monocots indicate that these miRNAs are not only conserved in sequence but also in their role in regulating phase transition. In addition, mature miRNA has been detected in various mosses, ferns, and gymnosperms (Arazi et al. 2005; Zhang et al. 2006; Axtell and Bowman 2008; Cuperus et al. 2011). In contrast to miR156, miR172 appears to be angiosperm specific, and it has not been cloned from other land plants (Axtell and Bowman 2008; Cuperus et al. 2011), even though the expression of miR172 has been detected by microarrays of RNA extracted from ferns (Axtell and Bowman 2008) and has been computationally predicted in Physcomitrella (Fattash et al. 2007). However, whether these miRNAs have a role in controlling thermosensory flowering time in other plants remains to be investigated.

\section{Nutrients Signaling to Flowering}

Sugars are the main source of carbon and energy for most cell types. For that reason, sugars have been recruited as key regulators of metabolic processes, but they are also involved in the regulation of many other physiological and developmental processes. Its widespread function has contributed to the increase in diversification and plasticity of higher eukaryotes, a phenomenon that acquires an enormous importance in photosynthetic and sessile organism like plants. Therefore, plants have developed more complex and flexible regulatory mechanisms than the rest of higher eukaryotes, and one of such processes is flowering (Rolland et al. 2006). In unicellular algae, routes controlled by sugars are poorly known, and sugar sensing has been involved in metabolic processes such as amino acid transport and astaxanthin biosynthesis in Chlorella (Kato and Imamura 2008; Li et al. 2008).

While temperature and photoperiodic signals are key external factors in the Arabidopsis floral transition, internal factors such as hormones, nutrients, or plant 
age have also a strong influence on flowering time (Amasino 2010; Fornara et al. 2010). However, the connection between carbohydrates and flowering is not entirely understood. There are numerous physiological studies showing the effect of sugars in flowering time in different species (Bernier et al. 1993; Lebon et al. 2008), although it is not clear whether they act to promote flowering (Corbesier et al. 1998; Roldan et al. 1999; Wahl et al. 2013) or as floral inhibitors (Zhou et al. 1998; Ohto et al. 2001). The induction of flowering is also associated with the mobilization of starch reserves and a transient increase in carbohydrate transport to the shoot apical meristem (SAM) during the floral transition (Corbesier et al. 1998). Recent studies have shown that this mechanism is controlled by $\mathrm{CO}$, the central photoperiod regulator (Ortiz-Marchena et al. 2014). Interestingly, this process seems to be conserved throughout evolution, as the ancestral $\mathrm{CO}$ homolog, $\mathrm{CrCO}$, is also involved in the photoperiodic control of starch accumulation in Chlamydomonas (Serrano et al. 2009; Romero and Valverde 2009; Valverde 2011).

It has been shown that trehalose-6-phosphate (T6P) affects flowering in Arabidopsis WT plants, so that an increase in sucrose during the floral transition would be signaled by an increase in T6P (Wahl et al. 2013). Plants with abnormal levels of T6P have altered flowering time. Thereby, high levels of T6P would induce the floral transition and vice versa (Schluepmann et al. 2003; Wahl et al. 2013). FT expression is reduced in plants with low amount of T6P, so it could be possible that T6P promotes flowering through activation of the florigen (Wahl et al. 2013). Therefore, it has been suggested that T6P promotes flowering when carbohydrate levels are high, influencing the photoperiod pathway (Tsai and Gazzarrini 2014). In this sense, T6P signal could affect flowering through miR156 and SPL (Matsoukas et al. 2012), so that T6P inhibits miRNA156 expression and SPL is then able to promote the floral transition (Wahl et al. 2013). Although in green algae T6P regulatory function is unknown, its biosynthetic mechanism is conserved in all algae and even in bacteria (Avonce et al. 2010; Michel et al. 2010; Deng et al. 2014; Pade et al. 2014).

In plants, transcriptional regulation by sugars interacts with signaling pathways mediated by hormones, although the mechanism by which this occurs is unknown. Evidence suggests that it is probably due to direct interactions between protein components of both routes in complexes, although there may also be indirect interactions (Gibson 2004; Jossier et al. 2009). Hexose levels, such as glucose and fructose, for example, are sensed by HEXOKINASE1 (HXK1). HXK1 is a glucose-phosphorylating enzyme that exerts a dual function as sugar sensor and hexose kinase. Both functions are independent, so that the metabolism of the hexose phosphate is not involved in the signaling function (Loreti et al. 2000; Moore et al. 2003; Valverde et al. 2005). The conservation of some steps in the signal cascade of sugar sensing is still in controversy. However, HXK is considered a conserved glucose sensor among algae, yeast, plants and animals (Pego et al. 2000; Li et al. 2008; Oesterhelt and Gross 2014).

Two other important systems regulate sugar signaling in plants, the Snf1-related kinase 1 (SnRK1) and the target of rapamycin (TOR) kinase. Both of them are central regulators that sense nutrient levels and promote or inhibit growth in an 
antagonistic way: low sugar levels promote $S n R K 1$ expression and high sugar levels upregulate TOR activity (Deprost et al. 2007; Smeekens et al. 2010; Robaglia et al. 2012). Although there are two possible orthologs of SnRKI annotated in the Chlamydomonas genome, there is no evidence about its functions. However, TOR is a central regulator of cell growth in all eukaryotes (Crespo 2012), and Chlamydomonas is no exception as TOR is regulated by nutrients (Crespo et al. 2005). Recently, T6P has been shown to inhibit SnRK1 activity in Arabidopsis (Zhang et al. 2009). T6P seems to have this function also in monocots, indicating a conserved role for this sugar (Zhang et al. 2009; Wu and Birch 2010; Debast et al. 2011; Martinez-Barajas et al. 2011; Nunes et al. 2013; Lawlor and Paul 2014). Both T6P and SnRK1 have opposite functions as major regulators of gene expression related to growth and energy (Baena-González and Sheen 2008; Zhang et al. 2009).

It has also been reported in Arabidopsis that EXORDIUM (EXO) and EXO-LIKE genes control growth on different environmental conditions through the response to brassinosteroids (Schroder et al. 2009). EXO proteins seem to modify the response to sugars in seedlings and to control general gene expression by sugars and the accumulation of starch mediated by sugars, ABA, and anthocyanins. Therefore, EXO protein would establish a balance between the levels of external carbon available for plant and the cell status (Lisso et al. 2013). In green algae, it has been shown that brassinosteroids and auxins work synergistically in the control of growth and metabolism (Bajguz and Piotrowska-Niczyporuk 2013), but until now, no EXO homolog has been described in any algal genome.

All these premises suggest that sugar sensing is an ancient, flexible regulatory mechanism that evolved, using ancestral elements, according to the needs of each organism.

Although sugars play an important role in the floral transition, nitrogen (N) availability also influences flowering time (Frink et al. 1999). $\mathrm{N}$ is an essential macronutrient and specifically $\mathrm{N}$ deprivation induces early flowering in different plants including Arabidopsis (Dickens and Staden 1988; Bernier et al. 1993; Loeppky and Coulman 2001; Castro Marin et al. 2011; Kant et al. 2011; Liu et al. 2013). Under $\mathrm{N}$ deprivation, the flowering integrators $F T, A P 1$, and $L E A F Y$ $(L F Y)$ are induced (Kant et al. 2011). Also, $C O$ expression is induced in low nitrate conditions and is repressed by high nitrate levels (Liu et al. 2013). On the other hand, spray of nitrate to stem and leaves induces flowering formation in mango trees in the tropics (Núñez-Elisea and Caldeira 1988). N also governs many processes in algae. In Chlamydomonas, $\mathrm{N}$ controls sexual life cycle (Goodenough et al. 2007), photosynthesis (Grossman 2000), and lipid induction (Sharma et al. 2012), among other processes. Nevertheless, the general regulatory mechanisms that connect $\mathrm{N}$ metabolism to developmental responses are widely unknown. 


\section{Flower Development}

Floral organogenesis is a natural extension of the floral transition process and shares many early genes involved in SAM differentiation and tissue organization. Floral integrators such as $F T, A P 1$, and $L F Y$ have a significant role in the early stages of floral tissue formation, and their mutation aborts the early differentiation process of the vegetative apical meristem into a reproductive meristem. In fact, flower appearance is extremely variable among species in size, shape, symmetry, and pigmentation, although the different whorls of organs originate from the floral meristem, a small group of undifferentiated cells. Typical angiosperm flowers consist of four organ types arranged in four concentric whorls at the tip of a floral shoot. From the outside to the inside of the flower, these organs are leaflike green sepals (whorl 1), generally colored petals (whorl 2), the male reproductive organs or stamens (whorl 3 ), and carpels (whorl 4), the female reproductive organs. During their life cycle, plants undergo several phase transitions in which miR156 and miR172 play an important role (Huijser and Schmid 2011; Poethig 2013; Wu and Poethig 2006). Among them, the vegetative-to-reproductive phase transition ends up with the formation of the flower. During this transition, the SAM changes to an inflorescence meristem (IM). The IM can be converted in a floral meristem (FM) or produce lateral meristems that will be, in turn, converted in a FM. The FM undergoes an early growth phase before the identity of the floral organs is established (McKim and Hay 2010). The characterization in Arabidopsis thaliana and Antirrhinum majus of different homeotic mutants in which the identity of floral organs was altered leads to the proposal of the ABC model for flower development (Haughn and Somerville 1988; Sommer et al. 1990; Coen et al. 1990, 1991; Yanofsky et al. 1990; Coen 1991; Carpenter and Coen 1990; Coen and Meyerowitz 1991; Schwarz-Sommer et al. 1990; Bowman et al. 1991). These homeotic mutants defined three overlapping functions, A, B, and C (Fig. 3), each operating in two adjacent whorls that specify the identity of the four floral organ types (Coen and Meyerowitz 1991). A-function mutants display carpels in the first whorl and stamens in the second whorl instead of sepal and petals, respectively. B-function mutants have sepals in the second whorl and carpels in the third whorl rather than petals and stamens. Finally, in C-function mutants petals substitute stamens in the third whorl and sepals carpels in the fourth whorl. Besides, C-function mutants are indeterminate and produce floral organs inside the fourth whorl. The A function acts alone in the outermost whorl (whorl 1) to specify sepal identity. A and B functions act in the second whorl to specify petals. The reproductive organs are specified by the action of $\mathrm{B}$ and $\mathrm{C}$ functions. Thus, stamens are determined by the joint action of $\mathrm{B}$ and $\mathrm{C}$ functions in the third whorl. At the center of the flower, in whorl 4, the $\mathrm{C}$ function acts alone to initiate carpel development and to terminate further development of the floral meristem. The ABC model also proposes that activity of $\mathrm{C}$ and $\mathrm{A}$ functions is mutually exclusive and $\mathrm{C}$ function is restricted to the third and fourth whorls by A function and vice versa (Fig. 3) (Coen and Meyerowitz 1991). Most floral homeotic genes controlling floral organ identity 


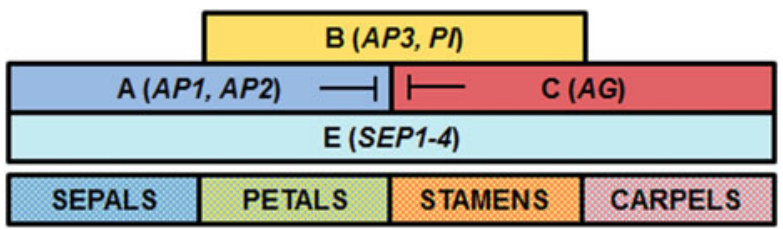

Fig. 3 Specification of floral organ identity. The combination of A, B, C, and E functions originates the specification of the four organ types. Arabidopsis genes responsible for the corresponding functions are indicated inside the expression domains of each function in a colorcoded pattern

encode MADS-box transcription factors (Meyerowitz 1997; Ng and Yanofsky 2001; Theissen 2001; Schwarz-Sommer et al. 1990; Krizek and Fletcher 2005; Lohmann and Weigel 2002; Jack 2001). MADS is an acronym for MCM1 (yeast), AGAMOUS (Arabidopsis), DEFICIENS (Antirrhinum), and SRF (human) on which the definition of this gene family was based (Schwarz-Sommer et al. 1990).

\subsection{Floral Identity Determination}

Plant floral meristem identity genes control floral meristem versus shoot/inflorescence fate (Bartlett et al. 2008). The meristem identity genes $L F Y$ and API in Arabidopsis and FLORICAULA (FLO) and SQUAMOSA (SQUA) in Antirrhinum induce flower development, whereas TERMINAL FLOWERI (TFL1) in Arabidopsis and CENTRORADIALIS (CEN) in Antirrhinum promote inflorescence development (Blazquez et al. 2006; Bradley et al. 1996; Alvarez et al. 1992; Coen et al. 1990; Huijser et al. 1992; Weigel et al. 1992; Mandel et al. 1992). Meristem identity genes are responsible for the determination of the floral meristem at the SAM for the control of the floral organ identity functions (mainly MADS-box genes). This transition represents the first step specific to floral development and is driven by the FLO/LFY genes. flo and lfy mutants produce proliferating inflorescence shoots instead of flowers (Coen et al. 1990; Schultz and Haughn 1991; Weigel et al. 1992). Homologs to FLO/LFY have been identified in many different plants and are present in most of the terrestrial plants analyzed, including mosses, ferns, gymnosperms, and angiosperms (Maizel et al. 2005).

The flowering signaling pathways responding to environmental, autonomous, and endogenous signals converge in the so-called floral integrators. FT-FD complex at the SAM induces flowering by activating SUPRESSOR OF OVEREXPRESSION OF CONSTANS 1 (SOC1), which in combination with AGAMOUS-LIKE 24 (AGL24) promotes the expression of the floral meristem identity gene $L F Y$ (Lee et al. 2008), which in turn will directly induce the expression of APl (Mandel and Yanofsky 1995; Parcy et al. 1998; Wagner et al. 1999). The $F T-F D$ complex also directly activates $A P l$ originating a feed-forward loop. Induction of $L F Y$ is also mediated by a set of different genes as SHOOT 
MERISTEMLESS (STM), PENNYWISE (PNY), POUND-FOOLISH (PNF), and SPL3 that activate $L F Y$ and thus the transition to FM (Yamaguchi et al. 2009; Lee et al. 2008; Kanrar et al. 2008; Smith et al. 2011; Pose et al. 2012; Wigge et al. 2005).

Although $L F Y$ is considered to be the main actor of this transition, other transcription factors from the MADS-box family as FUL and API are also necessary (Ferrandiz et al. 2000; Melzer et al. 2008; Bowman et al. 1993; Mandel and Yanofsky 1995; Weigel and Nilsson 1995) and are co-regulated with $L F Y$ by SPL3 (Yamaguchi et al. 2009; Huijser and Schmid 2011). LFY and API control the whole floral network regulating genes involved in the determinacy of the floral meristem and floral organ primordia (Coen et al. 1990; Benlloch et al. 2007; Weigel et al. 1992; Moyroud et al. 2009, 2010; Liu et al. 2009; Irish 2010) and constitute hubs that coordinate multiple processes and developmental pathways (O'Maoileidigh et al. 2014). $L F Y$ codes for a plant-specific transcription factor that is present as a single-copy gene in most angiosperms and binds to the regulatory regions of its target genes as a dimer with a DNA-binding domain structurally similar to the helix-turn-helix domain (Maizel et al. 2005; Benlloch et al. 2007; Hames et al. 2008; Parcy et al. 1998; Busch et al. 1999; Lamb et al. 2002; Lohmann et al. 2001; Moyroud et al. 2009). $L F Y$ is expressed at low levels in vegetative tissues, is upregulated in response to the flowering signals, and is expressed in the floral organ primordial where it participates in establishing specific gene expression patterns in the floral organ primordia.

Angiosperms evolved from gymnosperm ancestors at least 130-136 MYA, as evidenced by the earliest fossilized record of pollen from an apparent angiosperm known to date (Frohlich 2006). During plant evolution, several genome duplication events have occurred. However, as indicated before, $L F Y$ in angiosperms is a single-copy gene in most species with the exception of maize and Lamiales (Aagaard et al. 2006; Bomblies et al. 2003); thus, $L F Y$ can provide evidences on the evolutionary pace of plants. Some species exhibit various $L F Y$-like genes that have been shown to be paralogs acquired recently by polyploidy as in Nicotiana tabacum or from small-scale duplication events (Moyroud et al. 2009). On the other hand, gymnosperms usually present two paralogs, LFY and NEEDLY (NDLY) (Mellerowicz et al. 1998; Mouradov et al. 1998), originated in a gymnospermspecific duplication, with the $N D L Y$ lineage being lost in angiosperms (Frohlich and Estabrook 2000; Maizel et al. 2005; Himi et al. 2001; Frohlich 2003). Gymnosperm $L F Y$ homologs are mainly expressed in reproductive meristems and are able to complement Arabidopsis lfy mutants, indicating that LFY function is conserved between gymnosperms and angiosperms (Mouradov et al. 1998; Shindo et al. 2001; Maizel et al. 2005). Homologs of $L F Y$ have also been identified in ferns, mosses, and thallophytic green algae (Himi et al. 2001; Tanahashi et al. 2005; Sayou et al. 2014). Fern $L F Y$ homolog $C r L F Y 2$ can partially rescue the Arabidopsis lfy phenotype (Maizel et al. 2005). In the moss Physcomitrella patens, two LFY homologs have been identified $(P p L F 1,2)$ that have been shown to regulate cell division in the zygote (Tanahashi et al. 2005). PpLFY1 is unable to bind the 
sequence recognized by Arabidopsis LFY, although one amino acid substitution is sufficient for binding to a canonical LFY binding site (Maizel et al. 2005).

By analyzing the binding specificity of LFY homologs from different groups of plants, including green algae, it has been suggested that during evolution LFY modified its DNA binding specificity even though plant genomes generally contain a single $L F Y$ copy (Sayou et al. 2014). Gene duplication followed by sub-functionalization is a common mechanism in evolution. Duplicated genes loose the obligation to maintain its original function and can evolve to acquire new functions through mutations in their regulatory or coding regions. However, in the case of $L F Y$, the acquisition of the floral function seems to be related to changes in its DNA-binding domain (and probably in the cis-regulatory elements of its target genes) through an intermediate showing various binding specificities, thus avoiding deleterious effects (Sayou et al. 2014; Maizel et al. 2005; Della Pina et al. 2014; Kovach and Lamb 2014). The fact that $L F Y$ is present in multicellular and not in unicellular algae and that it is related to meristem organization suggests that $L F Y$ is associated to multicellularity, in contrast to COLs, DOFs, bHLHs, and other families of regulatory genes that originated in unicellular algae (Serrano et al. 2009; Romero-Campero et al. 2013).

\subsection{Floral Organ Identity Determination}

As indicated above, the floral meristem identity genes control the floral organ identity genes, whose mutation induces homeotic transformation of one organ into another. Genes that contribute to the A, B, and C functions are transcription factors and are known in different plants. In the case of Arabidopsis, AP1 and APETALA2 (AP2) are A-function genes, APETALA3 (AP3) and PISTILLATA (PI) are $\mathrm{B}$-function genes, and AGAMOUS (AG) is a C-function gene (Fig. 3) (Theissen 2001). The ABC function genes belong to the MADS-box family of transcription factors, with the exception of AP2, which belong to the AP2/ERF family (Jofuku et al. 1994; Weigel 1995; Okamuro et al. 1997; Riechmann and Meyerowitz 1998). The ABC model has been implemented by the identification and characterization of four MADS-box SEPALLATA genes (SEP1-4), which act redundantly and are required for the A, B, and C functions (Pelaz et al. 2000; Ditta et al. 2004), giving rise to the $\mathrm{ABCE}$ model for flower development (Wellmer et al. 2014; Theissen 2001). The ABCE functions would act in a combinatorial manner to specify each of the four floral organs. Thus, class A and E genes are necessary to specify sepals; class $\mathrm{B}$ and $\mathrm{E}$ genes are necessary to specify petals; class B, C, and E genes specify stamens; and finally class C and E genes specify carpels (Fig. 3) (Theissen 2001; Ditta et al. 2004; Theissen and Melzer 2007a).

According to the ABCE model, floral organ determination is accomplished by the formation of multimeric complexes of floral organ identity proteins that bind to two CArG boxes with a consensus sequence $\mathrm{CC}(\mathrm{A} / \mathrm{T})_{6} \mathrm{GG}$ (Wynne and Treisman 1992; Honma and Goto 2001). Analysis of the interaction between DEFICIENS 
(DEF), GLOBOSA (GLO), and SQUAMOSA (SQUA) from Antirrhinum majus provided the first evidences on the establishment of tetramers composed of a heterodimer DEF-GLO and a homodimer SQUA-SQUA (Egea-Cortines et al. 1999). DEF, GLO, and SQUA are the orthologs of Arabidopsis AP3, PI, and $A P 1$, respectively (Becker and Theissen 2003). Based on the observation that the SEP genes are also involved in the formation of petals, stamens, and carpels (Pelaz et al. 2000) and act as mediators of higher-order complex formation, the floral quartet model was coined as a mechanistic model for the determination of floral organs (Theissen and Saedler 2001; Honma and Goto 2001; Wellmer et al. 2014; Theissen and Melzer 2007b; Melzer and Theissen 2009; Erdmann et al. 2010; Melzer et al. 2009; Jetha et al. 2015). The floral quartet model indicates that specification of floral organs is mediated by the combinatorial formation of tetramers of MADS-domain proteins, although it has also been shown that floral organ identity MADS-box proteins interact with other types of proteins as chromatinassociated proteins and other transcription factors to establish higher-order complexes (Smaczniak et al. 2012a, b; Wellmer et al. 2014; O’Maoileidigh et al. 2014; Simonini et al. 2012; Liu et al. 2009).

MADS-box genes constitute a large family that has been divided in two main lineages, type I and type II, which are present in plants, animals, and fungi (Alvarez-Buylla et al. 2000a). Members of the MADS-box transcription family are characterized for the presence of a highly conserved MADS-box with a length of about 180 nucleotides that codes for the DNA binding to the CArG box (AlvarezBuylla et al. 2000b; Theissen et al. 2000; Riechmann and Meyerowitz 1997). The MADS-box genes in plants, with more than 100 members, were initially implicated in floral organ specification, although it has been shown to participate in many different developmental processes during the life cycle of plants (Smaczniak et al. 2012a; De Bodt et al. 2005). The family of MADS-box genes increased considerably during evolution by duplication-divergence-specialization of individual paralogs. Type I MADS-box genes form a heterogeneous group that just share the MADS domain (Kofuji et al. 2003; Parenicova et al. 2003; De Bodt et al. 2003). Type I and II MADS-box genes have been identified in all land plant lineages, from bryophytes to angiosperms. Their number and their functional diversity increased considerably during evolution (Becker and Theissen 2003; Kramer and Hall 2005; Kaufmann et al. 2005; Gramzow and Theissen 2010). Recently, several type I MADS-box genes have been shown to have regulatory roles in different aspects of plant reproduction as female gametogenesis and seed development (Masiero et al. 2011; Portereiko et al. 2006; Steffen et al. 2008; Kang et al. 2008). It has also been suggested that type I MADS-box proteins form heteromeric complexes (de Folter et al. 2005). The MADS-box type II lineage includes the floral homeotic genes as well as genes participating in embryogenesis, flowering time, and fruit development, among others (Smaczniak et al. 2012a). Type II MADS-box genes are characterized for having an N-terminal MADS domain, an intervening domain (I) and a keratin-like domain $(\mathrm{K})$ that are essential for protein-protein interaction, and a very variable C-terminal domain, thus named MIKC-type MADS-box (Kaufmann et al. 2005; Smaczniak et al. 2012a). MIKC-type has been subdivided 
in two groups, MIKCc and MIKC** the latter generally having a longer $\mathrm{K}$ domain (Henschel et al. 2002; Kwantes et al. 2012; Smaczniak et al. 2012a), that have been characterized in seed plants, pteridophytes, and mosses, indicating that the two groups diverged before the separation of mosses and land plants. In the unicellular green and red algae Chlamydomonas reinhardtii and Cyanidioschyzon merolae, respectively, a single MADS-box gene, lacking the I, C, and $\mathrm{K}$ domains, has been identified (Tanabe et al. 2005). However, MIKC-type MADS-box genes have been characterized in charophycean green algae, having a role in haploid reproductive development during the gametophytic phase (Tanabe et al. 2005). Land plants originated from multicellular charophycean algae about 500 MYA (Graham et al. 2000); thus, MIKC-type MADS-box genes might be recruited to form higher-order complexes before the origin of land plants. The fact that all the charophycean algae MADS-box genes characterized belong to the MIKCc type indicates that they are ancestral to the MIKC* type (Tanabe et al. 2005) and that $\mathrm{MICK}^{*}$-type genes evolved in the charophycean-land plant lineage after its divergence from Chlamydomonas. Considering that mosses and club moss (lycophyte) (Henschel et al. 2002), and the rest of land plant lineages, have both types of MIKC genes, it can be assumed that the last common ancestor of mosses and land plants (about 450 MYA) already had both types of MIKC MADS-box genes.

MADS-box genes are generally associated with the development of reproduction in extant land plant, mosses, and green algae relatives. However, extensive duplication events followed by specialization gave rise to a plethora of MADS-box genes involved in many different aspects of plant life cycle other than reproductive processes (Smaczniak et al. 2012a). Many different target genes involved in transcriptional and cellular signaling have been identified for FLC, SEP3, and AP1 (Deng et al. 2011; Kaufmann et al. 2009, 2010; Ito 2011; Dornelas et al. 2011), so the complexity of MADS-box transcription factors at the level of number of members, functions, spatiotemporal expression, posttranscriptional regulation, establishment of high-order complexes, and their putative role in more than organ or developmental stage will require the use of massive analysis techniques to generate a global framework to understand the evolution of this transcription factor family. Besides, the characterization of gene regulatory networks (GRN) will also provide primordial information to the study of MADs-box genes (Espinosa-Soto et al. 2004; van Mourik et al. 2010).

\section{Conclusions}

The study of the flowering pathways during the evolutionary history of plants unveils regulatory aspects that cannot be deduced from the study of single stories within the same species. We have learned that some of these regulatory pathways are conformed by a set of evolutionarily conserved genes that share even the same hierarchical regulatory mechanisms and modules. These "toolkits" were present as simple, short pathways in unicellular algae and evolved to long, complex ones in 
angiosperms. The addition of gene copies and new regulatory modules seem to have been a constant in many of the flowering pathways that allowed modern plant to respond with high efficiency to changing environmental conditions. This plasticity is essential to assure that flowering, and thus seed release, will be planned ahead and triggered at the moment of the year that guarantees a successful offspring for the species. This is of course intertwined with other signals such as the synchronicity with pollinator's signals and competing species that are too complex to discover in a direct analysis, but perhaps will become easier to understand if we learn to identify the gene toolkits and basic mechanism that rule these transitions.

The advent of massive analysis techniques is allowing us the rigorous and systematic study of non-model plant species. This information is being fed to computational analysis built upon the regulatory pathways constructed in model species. Surprisingly, these analyses have revealed a lot of homogeneity in the flowering pathways even among very different plant families. Therefore, it seems plausible to believe that these signaling mechanisms were mastered in the early flowering plants, were recruited from mechanisms that triggered developmental decisions in primitive plants, and have thus remained relatively unchanged during evolution due to their importance. This evolution and development perspective could allow us to better understand the response of plants to the incoming changing environmental conditions, intensified by human activity, and develop strategies to make plants flower at the correct time of the year in order to better perpetuate their species and ours.

Acknowledgments The authors would like to thank the help from the coordinated projects BIO2011-28847-C02-00 and BIO2014-52425-P to FV and JMR, the BIO2013-44078-P project to MC, and the TRANSPLANTA Consolider 28317 project from Spanish Ministry of Economy and Innovation (MINECO). The help from the Marie Curie Grant ID333748 to MC and from the Excellence Project P08-AGR-03582 and CVI-281 to FV from the Andalusian Government is also acknowledged. The authors regret the exclusion, due to lack of space, of excellent works from other colleagues that could not be referred in this review.

\section{References}

Aagaard JE, Willis JH, Phillips PC (2006) Relaxed selection among duplicate floral regulatory genes in Lamiales. J Mol Evol 63:493-503

Alvarez J, Guli CL, Yu X-H, Smyth DR (1992) Terminal flower: a gene affecting inflorescence development in Arabidopsis thaliana. Plant J 2:103-116

Alvarez-Buylla ER, Liljegren SJ, Pelaz S, Gold SE, Burgeff C, Ditta GS, Vergara-Silva F, Yanofsky MF (2000a) MADS-box gene evolution beyond flowers: expression in pollen, endosperm, guard cells, roots and trichomes. Plant J 24:457-466

Alvarez-Buylla ER, Pelaz S, Liljegren SJ, Gold SE, Burgeff C, Ditta GS, Ribas de Pouplana L, Martinez-Castilla L, Yanofsky MF (2000b) An ancestral MADS-box gene duplication occurred before the divergence of plants and animals. Proc Natl Acad Sci USA 97:5328-5333

Amasino R (2004) Vernalization, competence, and the epigenetic memory of winter. Plant Cell $16: 2553-2559$

Amasino R (2010) Seasonal and developmental timing of flowering. Plant J 61:1001-1013 
Amasino RM, Michaels SD (2010) The timing of flowering. Plant Physiol 154:516-520

Andrés F, Coupland G (2012) The genetic basis of flowering responses to seasonal cues. Nat Rev Genet 13:627-639

Arazi T, Talmor-Neiman M, Stav R, Riese M, Huijser P, Baulcombe DC (2005) Cloning and characterization of micro-RNAs from moss. Plant J 43:837-848

Aukerman MJ, Sakai H (2003) Regulation of flowering time and floral organ identity by a MicroRNA and its APETALA2-like target genes. Plant Cell 15:2730-2741

Avonce N, Wuyts J, Verschooten K, Vandesteene L, Van Dijck P (2010) The Cytophaga hutchinsonii ChTPSP: first characterized bifunctional TPS-TPP protein as putative ancestor of all eukaryotic trehalose biosynthesis proteins. Mol Biol Evol 27:359-369

Axtell MJ, Bowman JL (2008) Evolution of plant microRNAs and their targets. Trends Plant Sci 13:343-349

Baena-González E, Sheen J (2008) Convergent energy and stress signaling. Trends Plant Sci 13:474-482

Bajguz A, Piotrowska-Niczyporuk A (2013) Synergistic effect of auxins and brassinosteroids on the growth and regulation of metabolite content in the green alga Chlorella vulgaris (Trebouxiophyceae). Plant Physiol Biochem 71:290-297

Balasubramanian S, Weigel D (2006) Temperature induced flowering in Arabidopsis thaliana. Plant Signal Behav 1:227-228

Bartlett ME, Kirchoff BK, Specht CD (2008) Epi-illumination microscopy coupled to in situ hybridization and its utility in the study of evolution and development in non-model species. Dev Genes Evol 218:273-279

Bastow R, Mylne JS, Lister C, Lippman Z, Martienssen RA, Dean C (2004) Vernalization requires epigenetic silencing of FLC by histone methylation. Nature 427:164-167

Becker A, Theissen G (2003) The major clades of MADS-box genes and their role in the development and evolution of flowering plants. Mol Phylogenet Evol 29:464-489

Beel B, Müller N, Kottke T, Mittag M (2013) News about cryptochrome photoreceptors in algae. Plant Signal Behav 8:e22870

Benlloch R, Berbel A, Serrano-Mislata A, Madueño F (2007) Floral initiation and inflorescence architecture: a comparative view. Ann Bot 100:659-676

Bernier G, Havelange A, Houssa C, Petitjean A, Lejeune P (1993) Physiological signals that induce flowering. Plant Cell 5:1147-1155

Blazquez MA, Ahn JH, Weigel D (2003) A thermosensory pathway controlling flowering time in Arabidopsis thaliana. Nat Genet 33:168-171

Blazquez MA, Ferrándiz C, Madueño F, Parcy F (2006) How floral meristems are built. Plant Mol Biol 60:855-870

Böhlenius H, Huang T, Charbonnel-Campaa L, Brunner AM, Jansson S, Strauss SH, Nilsson O (2006) CO/FT regulatory module controls timing of flowering and seasonal growth cessation in trees. Science 312:1040-1043

Bomblies K, Wang RL, Ambrose BA, Schmidt RJ, Meeley RB, Doebley J (2003) Duplicate FLORICAULA/LEAFY homologs zfl1 and zfl2 control inflorescence architecture and flower patterning in maize. Development 130:2385-2395

Bouget FY, Lefranc M, Thommen Q, Pfeuty B, Lozano JC, Schatt P, Botebol H, Vergé V (2014) Transcriptional versus non-transcriptional clocks: a case study in Ostreococcus. Mar Genomics $14: 1-6$

Bowman JL, Smyth DR, Meyerowitz EM (1991) Genetic interactions among floral homeotic genes of Arabidopsis. Development 112:1-20

Bowman JL, Alvarez J, Weigel D, Meyerowitz EM, Smyth DR (1993) Control of flower development in Arabidopsis thaliana by APETALA1 and interacting genes. Development 119:721-743

Bradley D, Carpenter R, Copsey L, Vincent C, Rothstein S, Coen E (1996) Control of inflorescence architecture in Antirrhinum. Nature 379:791-797 
Bradshaw WE, Holzapfel CM (2007) Evolution of animal photoperiodism. Annu Rev Ecol Evol Syst 38:1-25

Busch MA, Bomblies K, Weigel D (1999) Activation of a floral homeotic gene in Arabidopsis. Science 285:585-587

Carpenter R, Coen ES (1990) Floral homeotic mutations produced by transposon-mutagenesis in Antirrhinum majus. Genes Dev 4:1483-1493

Carretero-Paulet L, Galstyan A, Roig-Villanova I, Martínez-García JF, Bilbao-Castro JR, Robertson DL (2010) Genome-wide classification and evolutionary analysis of the bHLH family of transcription factors in Arabidopsis, poplar, rice, moss, and algae. Plant Physiol 153:1398-1412

Casal JJ, Fankhauser C, Coupland G, Blázquez MA (2004) Signalling for developmental plasticity. Trends Plant Sci 9:309-314

Castro Marin I, Loef I, Bartetzko L, Searle I, Coupland G, Stitt M, Osuna D (2011) Nitrate regulates floral induction in Arabidopsis, acting independently of light, gibberellin and autonomous pathways. Planta 233:539-552

Chouard P (1960) Vernalization and its relations to dormancy. Annu Rev Plant Physiol 11:47

Coen ES (1991) The role of homeotic genes in flower development and evolution. Annu Rev Plant Physiol Plant Mol Biol 42:241-279

Coen ES, Meyerowitz EM (1991) The war of the whorls: genetic interactions controlling flower development. Nature 353:31-37

Coen ES, Romero JM, Doyle S, Elliott R, Murphy G, Carpenter R (1990) Floricaula: a homeotic gene required for flower development in antirrhinum majus. Cell 63:1311-1322

Coen ES, Doyle S, Romero JM, Elliott R, Magrath R, Carpenter R (1991) Homeotic genes controlling flower development in Antirrhinum. Development 113:149-155

Corbesier L, Lejeune P, Bernier G (1998) The role of carbohydrates in the induction of flowering in Arabidopsis thaliana: comparison between the wild type and a starchless mutant. Planta 206:131-137

Corellou F, Schwartz C, Motta JP, Djouani-Tahri EB, Sanchez F, Bouget FY (2009) Clocks in the green lineage: comparative functional analysis of the circadian architecture of the picoeukaryote ostreococcus. Plant Cell 21:3436-3449

Corrales AR, Nebauer SG, Carrillo L, Fernández-Nohales P, Marqués J, Renau-Morata B, Granell A, Pollmann S, Vicente-Carbajosa J, Molina RV, Medina J (2014) Characterization of tomato Cycling Dof Factors reveals conserved and new functions in the control of flowering time and abiotic stress responses. J Exp Bot 65:995-1012

Crespo JL (2012) BiP links TOR signaling to ER stress in Chlamydomonas. Plant Signal Behav 7:273-275

Crespo L, Díaz-Troya S, Florencio FJ (2005) Inhibition of target of rapamycin signaling by rapamycin in the unicellular green alga. Plant Physiol 139:1736-1749

Crevillen P, Dean C (2011) Regulation of the floral repressor gene FLC: the complexity of transcription in a chromatin context. Curr Opin Plant Biol 14:38-44

Crevillen P, Sonmez C, Wu Z, Dean C (2013) A gene loop containing the floral repressor FLC is disrupted in the early phase of vernalization. EMBO J 32:140-148

Cuperus JT, Fahlgren N, Carrington JC (2011) Evolution and functional diversification of MIRNA genes. Plant Cell 23:431-442

Danyluk J, Perron A, Houde M, Limin A, Fowler B, Benhamou N, Sarhan F (1998) Accumulation of an acidic dehydrin in the vicinity of the plasma membrane during cold acclimation of wheat. Plant Cell 10:623-638

De Bodt S, Raes J, Florquin K, Rombauts S, Rouze P, Theissen G, Van de Peer Y (2003) Genomewide structural annotation and evolutionary analysis of the type I MADS-box genes in plants. J Mol Evol 56:573-586

De Bodt S, Maere S, Van de Peer Y (2005) Genome duplication and the origin of angiosperms. Trends Ecol Evol 20:591-597 
de Folter S, Immink RG, Kieffer M, Parenicova L, Henz SR, Weigel D, Busscher M, Kooiker M, Colombo L, Kater MM, Davies B, Angenent GC (2005) Comprehensive interaction map of the Arabidopsis MADS Box transcription factors. Plant Cell 17:1424-1433

De Lucia F, Crevillen P, Jones AM, Greb T, Dean C (2008) A PHD-polycomb repressive complex 2 triggers the epigenetic silencing of FLC during vernalization. Proc Natl Acad Sci USA 105:16831-16836

Debast S, Nunes-Nesi A, Hajirezaei MR, Hofmann J, Sonnewald U, Fernie AR, Bornke F (2011) Altering trehalose-6-phosphate content in transgenic potato tubers affects tuber growth and alters responsiveness to hormones during sprouting. Plant Physiol 156:1754-1771

Della Pina S, Souer E, Koes R (2014) Arguments in the evo-devo debate: say it with flowers! J Exp Bot 65:2231-2242

Deng W, Ying H, Helliwell CA, Taylor JM, Peacock WJ, Dennis ES (2011) FLOWERING LOCUS C (FLC) regulates development pathways throughout the life cycle of Arabidopsis. Proc Natl Acad Sci USA 108:6680-6685

Deng Y, Wang X, Guo H, Duan D (2014) A trehalose-6-phosphate synthase gene from Saccharina japonica (Laminariales, Phaeophyceae). Mol Biol Rep 41:529-536

Deprost D, Yao L, Sormani R, Moreau M, Leterreus G, Nicolai M, Bedu M, Robaglia C, Meyer C (2007) The Arabidopsis TOR kinase links plant growth, yield, stress resistance and mRNA translation. EMBO Rep 8:864-870

Derkacheva M, Hennig L (2014) Variations on a theme: polycomb group proteins in plants. J Exp Bot 65:2769-2784

Dickens CWS, Staden JV (1988) The in vitro flowering of Kalanchöe blossfeldiana Poellnitz: I. Role of culture conditions and nutrients. J Exp Bot 39:461-471

Distelfeld A, Li C, Dubcovsky J (2009) Regulation of flowering in temperate cereals. Curr Opin Plant Biol 12:178-184

Ditta G, Pinyopich A, Robles P, Pelaz S, Yanofsky MF (2004) The SEP4 gene of Arabidopsis thaliana functions in floral organ and meristem identity. Curr Biol 14:1935-1940

Djouani-Tahri EB, Christie JM, Sanchez-Ferandin S, Sanchez F, Bouget FY, Corellou F (2011) A eukaryotic LOV-histidine kinase with circadian clock function in the picoalga Ostreococcus. Plant J 65:578-588

Doi K, Izawa T, Fuse T, Yamanouchi U, Kubo T, Shimatani Z, Yano M, Yoshimura A (2004) Ehd1, a B-type response regulator in rice, confers short-day promotion of flowering and controls FT-like gene expression independently of Hd1. Genes Dev 2:926-936

Dornelas MC, Patreze CM, Angenent GC, Immink RG (2011) MADS: the missing link between identity and growth? Trends Plant Sci 16:89-97

Dubcovsky J, Loukoianov A, Fu D, Valarik M, Sanchez A, Yan L (2006) Effect of photoperiod on the regulation of wheat vernalization genes VRN1 and VRN2. Plant Mol Biol 60:469-480

Egea-Cortines M, Saedler H, Sommer H (1999) Ternary complex formation between the MADSbox proteins SQUAMOSA, DEFICIENS and GLOBOSA is involved in the control of floral architecture in Antirrhinum majus. EMBO J 18:5370-5379

Erdmann R, Gramzow L, Melzer R, Theissen G, Becker A (2010) GORDITA (AGL63) is a young paralog of the Arabidopsis thaliana B(sister) MADS box gene ABS (TT16) that has undergone neofunctionalization. Plant J 63:914-924

Espinosa-Soto C, Padilla-Longoria P, Alvarez-Buylla ER (2004) A gene regulatory network model for cell-fate determination during Arabidopsis thaliana flower development that is robust and recovers experimental gene expression profiles. Plant Cell 16:2923-2939

Fang Q, Liu J, Xu Z, Song R (2008) Cloning and characterization of a flowering time gene from Thellungiella halophila. Acta Biochim Biophys Sin (Shanghai) 40:747-753

Fattash I, Voss B, Reski R, Hess WR, Frank W (2007) Evidence for the rapid expansion of microRNA-mediated regulation in early land plant evolution. BMC Plant Biol 7:13

Ferrandiz C, Gu Q, Martienssen R, Yanofsky MF (2000) Redundant regulation of meristem identity and plant architecture by FRUITFULL, APETALA1 and CAULIFLOWER. Development 127:725-734 
Finnegan EJ, Dennis ES (2007) Vernalization-induced trimethylation of histone H3 lysine 27 at FLC is not maintained in mitotically quiescent cells. Curr Biol 17:1978-1983

Fornara F, Panigrahi KCS, Gissot L, Sauerbrunn N, Rühl M, Jarillo JA, Coupland G (2009) Arabidopsis DOF transcription factors act redundantly to reduce CONSTANS expression and are essential for a photoperiodic flowering response. Dev Cell 17:75-86

Fornara F, de Montaigu A, Coupland G (2010) SnapShot: control of flowering in Arabidopsis. Cell 141:551-552

Frink CR, Waggoner PE, Ausubel JH (1999) Nitrogen fertilizer: retrospect and prospect. Proc Natl Acad Sci USA 96:1175-1180

Frohlich MW (2003) An evolutionary scenario for the origin of flowers. Nat Rev Genet 4:559-566

Frohlich MW (2006) Recent developments regarding the evolutionary origin of flowers. In: Soltis DE, Callow JA (eds) Advances in botanical research, vol 44. Academic Press, San Diego, CA, pp 63-127

Frohlich MW, Estabrook GF (2000) Wilkinson support calculated with exact probabilities: an example using Floricaula/LEAFY amino acid sequences that compares three hypotheses involving gene gain/loss in seed plants. Mol Biol Evol 17:1914-1925

Fu D, Dunbar M, Dubcovsky J (2007) Wheat VIN3-like PHD finger genes are up-regulated by vernalization. Mol Genet Genomics 277:301-313

Gazzani S, Gendall AR, Lister C, Dean C (2003) Analysis of the molecular basis of flowering time variation in Arabidopsis accessions. Plant Physiol 132:1107-1114

Geraldo N, Baurle I, Kidou S, Hu X, Dean C (2009) FRIGIDA delays flowering in Arabidopsis via a cotranscriptional mechanism involving direct interaction with the nuclear cap-binding complex. Plant Physiol 150:1611-1618

Gibson SI (2004) Sugar and phytohormone response pathways: navigating a signalling network. J Exp Bot 55:253-264

Goff SA, Ricke D, Lan TH, Presting G, Wang R, Dunn M, Glazebrook J, Sessions A, Oeller P, Varma $\mathrm{H}$ et al (2002) A draft sequence of the rice genome (Oryza sativa L. ssp. japonica). Science 296:92-100

González-Schain ND, Díaz-Mendoza M, Zurczak M, Suárez-López P (2012) Potato CONSTANS is involved in photoperiodic tuberization in a graft-transmissible manner. Plant J 70:678-690

Goodenough U, Lin H, Lee JH (2007) Sex determination in Chlamydomonas. Semin Cell Dev Biol 18:350-361

Graham LE, Cook ME, Busse JS (2000) The origin of plants: body plan changes contributing to a major evolutionary radiation. Proc Natl Acad Sci USA 97:4535-4540

Gramzow L, Theissen G (2010) A hitchhiker's guide to the MADS world of plants. Genome Biol $11: 214$

Greb T, Mylne JS, Crevillen P, Geraldo N, An H, Gendall AR, Dean C (2007) The PHD finger protein VRN5 functions in the epigenetic silencing of Arabidopsis FLC. Curr Biol 17:73-78

Greenup AG, Sasani S, Oliver SN, Walford SA, Millar AA, Trevaskis B (2011) Transcriptome analysis of the vernalization response in barley (Hordeum vulgare) seedlings. PLoS One 6: e17900

Grossman A (2000) Acclimation of Chlamydomonas reinhardtii to its nutrient environment. Protist 151:201-224

Halliday KJ, Salter MG, Thingnaes E, Whitelam GC (2003) Phytochrome control of flowering is temperature sensitive and correlates with expression of the floral integrator FT. Plant J 33:875-885

Hames C, Ptchelkine D, Grimm C, Thevenon E, Moyroud E, Gerard F, Martiel JL, Benlloch R, Parcy F, Muller CW (2008) Structural basis for LEAFY floral switch function and similarity with helix-turn-helix proteins. EMBO J 27:2628-2637

Hartmann U, Hohmann S, Nettesheim K, Wisman E, Saedler H, Huijser P (2000) Molecular cloning of SVP: a negative regulator of the floral transition in Arabidopsis. Plant J 21:351-360

Haughn GW, Somerville CR (1988) Genetic control of morphogenesis in Arabidopsis. Dev Genet 9:73-89 
Henschel K, Kofuji R, Hasebe M, Saedler H, Munster T, Theissen G (2002) Two ancient classes of MIKC-type MADS-box genes are present in the moss Physcomitrella patens. Mol Biol Evol 19:801-814

Heo JB, Sung S (2011) Vernalization-mediated epigenetic silencing by a long intronic noncoding RNA. Science 331:76-79

Higgins J, Bailey PC, Laurie DA (2010) Comparative genomics of flowering time pathways using Brachypodium distachyon as a model for the temperate grasses. PLoS One 5:e10065

Himi S, Sano R, Nishiyama T, Tanahashi T, Kato M, Ueda K, Hasebe M (2001) Evolution of MADS-box gene induction by FLO/LFY genes. J Mol Evol 53:387-393

Honma T, Goto K (2001) Complexes of MADS-box proteins are sufficient to convert leaves into floral organs. Nature 409:525-529

Huijser P, Schmid M (2011) The control of developmental phase transitions in plants. Development 138:4117-4129

Huijser P, Klein J, Lonnig WE, Meijer H, Saedler H, Sommer H (1992) Bracteomania, an inflorescence anomaly, is caused by the loss of function of the MADS-box gene squamosa in Antirrhinum majus. EMBO J 11:1239-1249

Imaizumi T, Schultz TF, Harmon FG, Ho LA, Kay SA (2005) FKF1 F-box protein mediates cyclic degradation of a repressor of CONSTANS in Arabidopsis. Science 309:293-297

Irish VF (2010) The flowering of Arabidopsis flower development. Plant J 61:1014-1028

Irwin JA, Lister C, Soumpourou E, Zhang Y, Howell EC, Teakle G, Dean C (2012) Functional alleles of the flowering time regulator FRIGIDA in the Brassica oleracea genome. BMC Plant Biol 12:21

Ito T (2011) Coordination of flower development by homeotic master regulators. Curr Opin Plant Biol 14:53-59

Ito S, Song YH, Josephson-Day AR, Miller RJ, Breton G, Olmstead RG, Imaizumi T (2012) FLOWERING BHLH transcriptional activators control expression of the photoperiodic flowering regulator CONSTANS in Arabidopsis. Proc Natl Acad Sci USA 109:3582-3587

Izawa T, Takahashi Y, Yano M (2003) Comparative biology comes into bloom: genomic and genetic comparison of flowering pathways in rice and Arabidopsis. Curr Opin Plant Biol 6:113-120

Jack T (2001) Plant development going MADS. Plant Mol Biol 46:515-520

Jang S, Marchal V, Panigrahi KCS, Wenkel S, Soppe W, Deng XW, Valverde F, Coupland G (2008) Arabidopsis COP1 shapes the temporal pattern of CO accumulation conferring a photoperiodic flowering response. EMBO J 27:1277-1288

Jetha K, Theissen G, Melzer R (2015) Arabidopsis SEPALLATA proteins differ in cooperative DNA-binding during the formation of floral quartet-like complexes. Nucleic Acids Res 42:10927-10942

Jofuku KD, den Boer BG, Van Montagu M, Okamuro JK (1994) Control of Arabidopsis flower and seed development by the homeotic gene APETALA2. Plant Cell 6:1211-1225

Johanson U, West J, Lister C, Michaels S, Amasino R, Dean C (2000) Molecular analysis of FRIGIDA, a major determinant of natural variation in Arabidopsis flowering time. Science 290:344-347

Jossier M, Bouly JP, Meimoun P, Arjmand A, Lessard P, Hawley S, Grahame Hardie D, Thomas M (2009) SnRK1 (SNF1-related kinase 1) has a central role in sugar and ABA signalling in Arabidopsis thaliana. Plant J 59:316-328

Kang IH, Steffen JG, Portereiko MF, Lloyd A, Drews GN (2008) The AGL62 MADS domain protein regulates cellularization during endosperm development in Arabidopsis. Plant Cell 20:635-647

Kanrar S, Bhattacharya M, Arthur B, Courtier J, Smith HM (2008) Regulatory networks that function to specify flower meristems require the function of homeobox genes PENNYWISE and POUND-FOOLISH in Arabidopsis. Plant J 54:924-937

Kant S, Peng M, Rothstein SJ (2011) Genetic regulation by NLA and microRNA827 for maintaining nitrate-dependent phosphate homeostasis in Arabidopsis. PLoS Genet 7:e1002021 
Kato Y, Imamura N (2008) Effect of sugars on amino acid transport by symbiotic Chlorella. Plant Physiol Biochem 46:911-917

Kaufmann K, Melzer R, Theissen G (2005) MIKC-type MADS-domain proteins: structural modularity, protein interactions and network evolution in land plants. Gene 347:183-198

Kaufmann K, Muino JM, Jauregui R, Airoldi CA, Smaczniak C, Krajewski P, Angenent GC (2009) Target genes of the MADS transcription factor SEPALLATA3: integration of developmental and hormonal pathways in the Arabidopsis flower. PLoS Biol 7:e1000090

Kaufmann K, Wellmer F, Muino JM, Ferrier T, Wuest SE, Kumar V, Serrano-Mislata A, Madueno F, Krajewski P, Meyerowitz EM, Angenent GC, Riechmann JL (2010) Orchestration of floral initiation by APETALA1. Science 328:85-89

Keller SR, Levsen N, Ingvarsson PK, Olson MS, Tiffin P (2011) Local selection across a latitudinal gradient shapes nucleotide diversity in balsam poplar, Populus balsamifera L. Genetics 188:941-952

Kim DH, Sung S (2013) Coordination of the vernalization response through a VIN3 and FLC gene family regulatory network in Arabidopsis. Plant Cell 25:454-469

Kim DH, Sung S (2014) Genetic and epigenetic mechanisms underlying vernalization. Arabidopsis Book 12:e0171

Kim DH, Doyle MR, Sung S, Amasino RM (2009) Vernalization: winter and the timing of flowering in plants. Annu Rev Cell Dev Biol 25:277-299

Kim JJ, Lee JH, Kim W, Jung HS, Huijser P, Ahn JH (2012) The microRNA156-SQUAMOSA PROMOTER BINDING PROTEIN-LIKE3 module regulates ambient temperature-responsive flowering via FLOWERING LOCUS T in Arabidopsis. Plant Physiol 159:461-478

Kloosterman B, Abelenda JA, Gomez MDMC, Oortwijn M, de Boer JM, Kowitwanich K, Horvath BM, van Eck HJ, Smaczniak C, Prat S, Visser RGF, Bachem CWB (2013) Naturally occurring allele diversity allows potato cultivation in northern latitudes. Nature 495:246-250

Kofuji R, Sumikawa N, Yamasaki M, Kondo K, Ueda K, Ito M, Hasebe M (2003) Evolution and divergence of the MADS-box gene family based on genome-wide expression analyses. Mol Biol Evol 20:1963-1977

Kovach JD, Lamb RS (2014) There can be only one. Science 343:623-624

Koyama K, Hatano H, Nakamura J, Takumi S (2012) Characterization of three VERNALIZATION INSENSITIVE3-like (VIL) homologs in wild wheat, Aegilops tauschii Coss. Hereditas 149:62-71

Kramer EM, Hall JC (2005) Evolutionary dynamics of genes controlling floral development. Curr Opin Plant Biol 8:13-18

Krizek BA, Fletcher JC (2005) Molecular mechanisms of flower development: an armchair guide. Nat Rev Genet 6:688-698

Kuittinen H, Niittyvuopio A, Rinne P, Savolainen O (2008) Natural variation in Arabidopsis lyrata vernalization requirement conferred by a FRIGIDA indel polymorphism. Mol Biol Evol 25:319-329

Kumar SV, Wigge PA (2010) H2A.Z-containing nucleosomes mediate the thermosensory response in Arabidopsis. Cell 140:136-147

Kumar SV, Lucyshyn D, Jaeger KE, Alos E, Alvey E, Harberd NP, Wigge PA (2012) Transcription factor PIF4 controls the thermosensory activation of flowering. Nature 484:242-245

Kwantes M, Liebsch D, Verelst W (2012) How MIKC* MADS-box genes originated and evidence for their conserved function throughout the evolution of vascular plant gametophytes. Mol Biol Evol 29:293-302

Lamb RS, Hill TA, Tan QK, Irish VF (2002) Regulation of APETALA3 floral homeotic gene expression by meristem identity genes. Development 129:2079-2086

Lawlor DW, Paul MJ (2014) Source/sink interactions underpin crop yield: the case for trehalose 6-phosphate/SnRK1 in improvement of wheat. Front Plant Sci 5:418. doi:10.3389/fpls.2014. 00418 
Lazaro A, Valverde F, Pineiro M, Jarillo JA (2012) The Arabidopsis E3 Ubiquitin Ligase HOS1 negatively regulates CONSTANS abundance in the photoperiodic control of flowering. Plant Cell 24:982-999

Lebon G, Wojnarowiez G, Holzapfel B, Fontaine F, Vaillant-Gaveau N, Clement C (2008) Sugars and flowering in the grapevine (Vitis vinifera L.). J Exp Bot 59:2565-2578

Ledger S, Strayer C, Ashton F, Sa K, Putterill J (2001) Analysis of the function of two circadianregulated CONSTANS-LIKE genes. Plant J 26:15-22

Lee JH, Park SH, Lee JS, Ahn JH (2007) A conserved role of SHORT VEGETATIVE PHASE (SVP) in controlling flowering time of Brassica plants. Biochim Biophys Acta 1769:455-461

Lee J, Oh M, Park H, Lee I (2008) SOC1 translocated to the nucleus by interaction with AGL24 directly regulates leafy. Plant J 55:832-843

Lee H, Yoo SJ, Lee JH, Kim W, Yoo SK, Fitzgerald H, Carrington JC, Ahn JH (2010) Genetic framework for flowering-time regulation by ambient temperature-responsive miRNAs in Arabidopsis. Nucleic Acids Res 38:3081-3093

Lee JH, Ryu HS, Chung KS, Pose D, Kim S, Schmid M, Ahn JH (2013) Regulation of temperatureresponsive flowering by MADS-box transcription factor repressors. Science 342:628-632

Levy YY, Mesnage S, Mylne JS, Gendall AR, Dean C (2002) Multiple roles of Arabidopsis VRN1 in vernalization and flowering time control. Science 297:243-246

Li Y, Huang J, Sandmann G, Chen F (2008) Glucose sensing and the mitochondrial alternative pathway are involved in the regulation of astaxanthin biosynthesis in the dark-grown Chlorella zofingiensis (Chlorophyceae). Planta 228:735-743

Li D, Yang C, Li X, Gan Q, Zhao X, Zhu L (2009) Functional characterization of rice OsDof12. Planta 229:1159-1169

Li P, Filiault D, Box MS, Kerdaffrec E, van Oosterhout C, Wilczek AM, Schmitt J, McMullan M, Bergelson J, Nordborg M et al (2014) Multiple FLC haplotypes defined by independent cis-regulatory variation underpin life history diversity in Arabidopsis thaliana. Genes Dev 28: $1635-1640$

Lisso J, Schroder F, Mussig C (2013) EXO modifies sucrose and trehalose responses and connects the extracellular carbon status to growth. Front Plant Sci 4:219

Liu C, Xi W, Shen L, Tan C, Yu H (2009) Regulation of floral patterning by flowering time genes. Dev Cell 16:711-722

Liu T, Li Y, Ren J, Qian Y, Yang X, Duan W, Hou X (2013) Nitrate or NaCl regulates floral induction in Arabidopsis thaliana. Biologia 68:215-222

Loeppky HA, Coulman BE (2001) Residue removal and nitrogen fertilization affects tiller development and flowering in meadow bromegrass. Agron J 93:891-895

Lohmann JU, Weigel D (2002) Building beauty: the genetic control of floral patterning. Dev Cell 2:135-142

Lohmann JU, Hong RL, Hobe M, Busch MA, Parcy F, Simon R, Weigel D (2001) A molecular link between stem cell regulation and floral patterning in Arabidopsis. Cell 105:793-803

Loreti E, Matsukura C, Gubler F, Alpi A, Yamaguchi J, Perata P (2000) Glucose repression of alpha-amylase in barley embryos is independent of GAMYB transcription. Plant Mol Biol 44:85-90

Lovell JT, Juenger TE, Michaels SD, Lasky JR, Platt A, Richards JH, Yu X, Easlon HM, Sen S, McKay JK (2013) Pleiotropy of FRIGIDA enhances the potential for multivariate adaptation. Proc Biol Sci 280:20131043

Lucas-Reina E, Romero-Campero FJ, Romero JM, Valverde F (2015) An evolutionarily conserved DOF-CONSTANS module controls plant photoperiodic signalling. Plant Physiol 168(2):561574. doi: $10.1104 / \mathrm{pp} .15 .00321$

Luo M, Platten D, Chaudhury A, Peacock WJ, Dennis ES (2009) Expression, imprinting, and evolution of rice homologs of the polycomb group genes. Mol Plant 2:711-723

Maizel A, Busch MA, Tanahashi T, Perkovic J, Kato M, Hasebe M, Weigel D (2005) The floral regulator LEAFY evolves by substitutions in the DNA binding domain. Science 308:260-263 
Mandel MA, Yanofsky MF (1995) A gene triggering flower formation in Arabidopsis. Nature 377:522-524

Mandel MA, Gustafson-Brown C, Savidge B, Yanofsky MF (1992) Molecular characterization of the Arabidopsis floral homeotic gene APETALA1. Nature 360:273-277

Martinez-Barajas E, Delatte T, Schluepmann H, de Jong GJ, Somsen GW, Nunes C, Primavesi LF, Coello P, Mitchel RAC, Paul MJ (2011) Wheat grain development is characterized by remarkable trehalose 6-phosphate accumulation pregrain filling: tissue distribution and relationship to SNF1-related protein kinase1 activity. Plant Physiol 156:373-381

Martínez-García JF, Virgós-Soler A, Prat S (2002) Control of photoperiod-regulated tuberization in potato by the Arabidopsis flowering-time gene CONSTANS. Proc Natl Acad Sci USA 99:15211-15216

Masiero S, Colombo L, Grini PE, Schnittger A, Kater MM (2011) The emerging importance of type I MADS box transcription factors for plant reproduction. Plant Cell 23:865-872

Matsoukas IG, Massiah AJ, Thomas B (2012) Florigenic and antiflorigenic signaling in plants. Plant Cell Physiol 53:1827-1842

Matsuo T, Ishiura M (2011) Chlamydomonas reinhardtii as a new model system for studying the molecular basis of the circadian clock. FEBS Lett 585:1495-1502

McClung CR (2014) Wheels within wheels: new transcriptional feedback loops in the Arabidopsis circadian clock. F1000Prime Rep 6:2

McKim S, Hay A (2010) Patterning and evolution of floral structures-marking time. Curr Opin Genet Dev 20:448-453

Mellerowicz EJ, Horgan K, Walden A, Coker A, Walter C (1998) PRFLL-a Pinus radiata homologue of FLORICAULA and LEAFY is expressed in buds containing vegetative shoot and undifferentiated male cone primordia. Planta 206:619-629

Melzer R, Theissen G (2009) Reconstitution of 'floral quartets' in vitro involving class B and class E floral homeotic proteins. Nucleic Acids Res 37:2723-2736

Melzer S, Lens F, Gennen J, Vanneste S, Rohde A, Beeckman T (2008) Flowering-time genes modulate meristem determinacy and growth form in Arabidopsis thaliana. Nat Genet 40:1489-1492

Melzer R, Verelst W, Theissen G (2009) The class E floral homeotic protein SEPALLATA3 is sufficient to loop DNA in 'floral quartet'-like complexes in vitro. Nucleic Acids Res 37:144-157

Meyerowitz EM (1997) Plants and the logic of development. Genetics 145:5-9

Michaels SD, Amasino RM (1999) The gibberellic acid biosynthesis mutant ga1-3 of Arabidopsis thaliana is responsive to vernalization. Dev Genet 25:194-198

Michaels SD, Amasino RM (2001) Loss of FLOWERING LOCUS C activity eliminates the lateflowering phenotype of FRIGIDA and autonomous pathway mutations but not responsiveness to vernalization. Plant Cell 13:935-941

Michel G, Tonon T, Scornet D, Cock JM, Kloareg B (2010) Central and storage carbon metabolism of the brown alga Ectocarpus siliculosus: insights into the origin and evolution of storage carbohydrates in Eukaryotes. New Phytol 188:67-81

Moore B, Zhou L, Rolland F, Hall Q, Cheng WH, Liu YX, Hwang I, Jones T, Sheen J (2003) Role of the Arabidopsis glucose sensor HXK1 in nutrient, light, and hormonal signaling. Science 300:332-336

Moreno-Risueño MA, Martínez M, Vicente-Carbajosa J, Carbonero P (2007) The family of DOF transcription factors: from green unicellular algae to vascular plants. Mol Genet Genomics 277:379-390

Mouradov A, Glassick T, Hamdorf B, Murphy L, Fowler B, Marla S, Teasdale RD (1998) NEEDLY, a Pinus radiata ortholog of FLORICAULA/LEAFY genes, expressed in both reproductive and vegetative meristems. Proc Natl Acad Sci USA 95:6537-6542

Moyroud E, Tichtinsky G, Parcy F (2009) The LEAFY floral regulators in Angiosperms: conserved proteins with diverse roles. J Plant Biol 52:177-185 
Moyroud E, Kusters E, Monniaux M, Koes R, Parcy F (2010) LEAFY blossoms. Trends Plant Sci 15:346-352

Murphy RL, Klein RR, Morishige DT, Brady JA, Rooney WL, Miller FR, Dugas DV, Klein PE, Mullet JE (2011) Coincident light and clock regulation of pseudoresponse regulator protein 37 (PRR37) controls photoperiodic flowering in sorghum. Proc Natl Acad Sci USA 108:16469-16474

Nakamura Y, Kato T, Yamashino T, Murakami M, Mizuno T (2007) Characterization of a set of phytochrome-interacting factor-like bHLH proteins in Oryza sativa. Biosci Biotech Biochem 71:1183-1191

Navarro C, Ja A, Cruz-Oró E, Cuéllar Ca Tamaki S, Silva J, Shimamoto K, Prat S (2011) Control of flowering and storage organ formation in potato by FLOWERING LOCUS T. Nature 478:119-122

$\mathrm{Ng}$ M, Yanofsky MF (2001) Function and evolution of the plant MADS-box gene family. Nat Rev Genet 2:186-195

Noguero M, Atif RM, Ochatt S, Thompson RD (2013) The role of the DNA-binding One Zinc Finger (DOF) transcription factor family in plants. Plant Sci 209:32-45

Nunes C, Primavesi LF, Patel MK, Martinez-Barajas E, Powers SJ, Sagar R et al (2013) Inhibition of SnRK1 by metabolites: tissue-dependent effects and cooperative inhibition by glucose1phosphate in combination with trehalose-6-phosphate. Plant Physiol Biochem 63:89-98

Núñez-Elisea R, Caldeira ML (1988) Induction of flowering in mango (Mangifera indica L.) within ammonium nitrate sprays. HortSci 23:883

O'Maoileidigh DS, Graciet E, Wellmer F (2014) Gene networks controlling Arabidopsis thaliana flower development. New Phytol 201:16-30

Oesterhelt C, Gross W (2014) Different sugar kinases are involved in the sugar sensing of Galdieria sulphuraria. Plant Physiol 128:291-299

Ohto M, Onai K, Furukawa Y, Aoki E, Araki T, Nakamura K (2001) Effects of sugar on vegetative development and floral transition in Arabidopsis. Plant Physiol 127:252-261

Okamuro JK, Caster B, Villarroel R, Van Montagu M, Jofuku KD (1997) The AP2 domain of APETALA2 defines a large new family of DNA binding proteins in Arabidopsis. Proc Natl Acad Sci USA 94:7076-7081

Oliver SN, Finnegan EJ, Dennis ES, Peacock WJ, Trevaskis B (2009) Vernalization-induced flowering in cereals is associated with changes in histone methylation at the VERNALIZATIONI gene. Proc Natl Acad Sci USA 106:8386-8391

Oliver SN, Deng W, Casao MC, Trevaskis B (2013) Low temperatures induce rapid changes in chromatin state and transcript levels of the cereal VERNALIZATION1 gene. J Exp Bot 64:2413-2422

Ortiz-Marchena MI, Albi T, Lucas-Reina E, Said FE, Romero-Campero FJ, Cano B, Ruiz MT, Romero JM, Valverde F (2014) Photoperiodic control of carbon distribution during the floral transition in Arabidopsis thaliana. Plant Cell 26:565-584

Pade N, Linka N, Ruth W, Weber APM, Hagemann M (2014) Floridoside and isofloridoside are synthesized by trehalose 6-phosphate synthase-like enzymes in the red alga Galdieria sulphuraria. New Phytol 205(3):1227-1238. doi:10.1111/nph.13108

Parcy F, Nilsson O, Busch MA, Lee I, Weigel D (1998) A genetic framework for floral patterning. Nature 395:561-566

Parenicova L, de Folter S, Kieffer M, Horner DS, Favalli C, Busscher J, Cook HE, Ingram RM, Kater MM, Davies B, Angenent GC, Colombo L (2003) Molecular and phylogenetic analyses of the complete MADS-box transcription factor family in Arabidopsis: new openings to the MADS world. Plant Cell 15:1538-1551

Pego V, Kortstee AJ, Huijser C, Smeekens SCM (2000) Photosynthesis, sugars and the regulation of gene expression. J Exp Bot 51:407-416

Pelaz S, Ditta GS, Baumann E, Wisman E, Yanofsky MF (2000) B and C floral organ identity functions require SEPALLATA MADS-box genes. Nature 405:200-203 
Pin PA, Benlloch R, Bonnet D, Wremerth-Weich E, Kraft T, Gielen JJ, Nilsson O (2010) An antagonistic pair of FT homologs mediates the control of flowering time in sugar beet. Science 330:1397-1400

Piñeiro M, Jarillo JA (2013) Ubiquitination in the control of photoperiodic flowering. Plant Sci 198:98-109

Pires N, Dolan L (2010) Early evolution of bHLH proteins in plants. Plant Signal Behav 5:911-912

Poethig RS (2013) Vegetative phase change and shoot maturation in plants. Curr Top Dev Biol 105:125-152

Portereiko MF, Lloyd A, Steffen JG, Punwani JA, Otsuga D, Drews GN (2006) AGL80 is required for central cell and endosperm development in Arabidopsis. Plant Cell 18:1862-1872

Pose D, Yant L, Schmid M (2012) The end of innocence: flowering networks explode in complexity. Curr Opin Plant Biol 15:45-50

Pose D, Verhage L, Ott F, Yant L, Mathieu J, Angenent GC, Immink RG, Schmid M (2013) Temperature-dependent regulation of flowering by antagonistic FLM variants. Nature 503:414-417

Preston JC, Sandve SR (2013) Adaptation to seasonality and the winter freeze. Front Plant Sci 4:167

Pugsley AT (1971) A genetic analysis of the spring-winter habit of growth in wheat. Aust J Agric Res 22:10

Ratcliffe OJ, Nadzan GC, Reuber TL, Riechmann JL (2001) Regulation of flowering in Arabidopsis by an FLC homologue. Plant Physiol 126:122-132

Ratcliffe OJ, Kumimoto RW, Wong BJ, Riechmann JL (2003) Analysis of the Arabidopsis MADS AFFECTING FLOWERING gene family: MAF2 prevents vernalization by short periods of cold. Plant Cell 15:1159-1169

Ream TS, Woods DP, Amasino RM (2012) The molecular basis of vernalization in different plant groups. Cold Spring Harb Symp Quant Biol 77:105-115

Ream TS, Woods DP, Schwartz CJ, Sanabria CP, Mahoy JA, Walters EM, Kaeppler HF, Amasino RM (2014) Interaction of photoperiod and vernalization determines flowering time of Brachypodium distachyon. Plant Physiol 164:694-709

Reeves PA, He Y, Schmitz RJ, Amasino RM, Panella LW, Richards CM (2007) Evolutionary conservation of the FLOWERING LOCUS C-mediated vernalization response: evidence from the sugar beet (Beta vulgaris). Genetics 176:295-307

Reisdorph NA, Small GD (2004) The CPH1 gene of Chlamydomonas reinhardtii encodes two forms of cryptochrome whose levels are controlled by light-induced proteolysis 1 [w]. Plant Physiol 134:1546-1554

Riaño-Pachón DM, Corrêa LGG, Trejos-Espinosa R, Mueller-Roeber B (2008) Green transcription factors: a chlamydomonas overview. Genetics 179:31-39

Riechmann JL, Meyerowitz EM (1997) MADS domain proteins in plant development. Biol Chem 378:1079-1101

Riechmann JL, Meyerowitz EM (1998) The AP2/EREBP family of plant transcription factors. Biol Chem 379:633-646

Risk JM, Laurie RE, Macknight RC, Day CL (2010) FRIGIDA and related proteins have a conserved central domain and family specific $\mathrm{N}$ - and $\mathrm{C}$-terminal regions that are functionally important. Plant Mol Biol 73:493-505

Robaglia C, Thomas M, Meyer C (2012) Sensing nutrient and energy status by SnRK1 and TOR kinases. Curr Opin Plant Biol 57:301-307

Rockwell NC, Duanmu D, Martin SS, Bachy C, Price DC, Bhattacharya D, Worden AZ, Lagarias JC (2014) Eukaryotic algal phytochromes span the visible spectrum. Proc Natl Acad Sci USA 111:3871-3876

Roldan M, Gomez-Mena C, Ruiz-Garcia L, Salinas J, Martinez-Zapater JM (1999) Sucrose availability on the aerial part of the plant promotes morphogenesis and flowering of Arabidopsis in the dark. Plant J 20:581-590 
Rolland F, Baena-González E, Sheen J (2006) Sugar sensing and signaling in plants: conserved and novel mechanisms. Annu Rev Plant Biol 57:675-709

Romero JM, Valverde F (2009) Evolutionarily conserved photoperiod mechanisms in plants. Plant Signal Behav 4:642-644

Romero-Campero FJ, Lucas-Reina E, Said FE, Romero JM, Valverde F (2013) A contribution to the study of plant development evolution based on gene co-expression networks. Front Plant Sci 4:1-17

Rubio V, Deng XW (2007) Plant science: standing on the shoulders of GIGANTEA. Science 318:206-207

Ruelens P, de Maagd RA, Proost S, Theissen G, Geuten K, Kaufmann K (2013) FLOWERING LOCUS $\mathrm{C}$ in monocots and the tandem origin of angiosperm-specific MADS-box genes. Nat Commun 4:2280

Samach A, Wigge PA (2005) Ambient temperature perception in plants. Curr Opin Plant Biol 8:483-486

Sawa M, Kay SA (2011) GIGANTEA directly activates Flowering Locus T in Arabidopsis thaliana. Proc Natl Acad Sci USA 28:11698-11703

Sayou C, Monniaux M, Nanao MH, Moyroud E, Brockington SF, Thevenon E, Chahtane H, Warthmann N, Melkonian M, Zhang Y, Wong GK, Weigel D, Parcy F, Dumas R (2014) A promiscuous intermediate underlies the evolution of LEAFY DNA binding specificity. Science 343:645-648

Schluepmann H, Pellny T, van Dijken A, Smeekens S, Paul M (2003) Trehalose 6-phosphate is indispensable for carbohydrate utilization and growth in Arabidopsis thaliana. Proc Natl Acad Sci USA 100:6849-6854

Schranz ME, Quijada P, Sung SB, Lukens L, Amasino R, Osborn TC (2002) Characterization and effects of the replicated flowering time gene FLC in Brassica rapa. Genetics 162:1457-1468

Schroder F, Lisso J, Lange P, Mussig C (2009) The extracellular EXO protein mediates cell expansion in Arabidopsis leaves. BMC Plant Biol 9:20

Schultz EA, Haughn GW (1991) LEAFY, a homeotic gene that regulates inflorescence development in Arabidopsis. Plant Cell 3:771-781

Schulze T, Prager K, Dathe H, Kelm J, Kiessling P, Mittag M (2010) How the green alga Chlamydomonas reinhardtii keeps time. Protoplasma 244:3-14

Schwarz-Sommer Z, Huijser P, Nacken W, Saedler H, Sommer H (1990) Genetic control of flower development by homeotic genes in Antirrhinum majus. Science 250:931-936

Scortecci KC, Michaels SD, Amasino RM (2001) Identification of a MADS-box gene, FLOWERING LOCUS M, that represses flowering. Plant J 26:229-236

Serrano G, Herrera-palau R, Romero JM, Serrano A, Coupland G, Valverde F (2009) Chlamydomonas CONSTANS and the evolution of plant photoperiodic signaling. Curr Biol 19:359-368

Sharma KK, Schuhmann H, Schenk PM (2012) High lipid induction in microalgae for biodiesel production. Energies 5:1532-1553

Sheldon CC, Burn JE, Perez PP, Metzger J, Edwards JA, Peacock WJ, Dennis ES (1999) The FLF MADS box gene: a repressor of flowering in Arabidopsis regulated by vernalization and methylation. Plant Cell 11:445-458

Shindo S, Sakakibara K, Sano R, Ueda K, Hasebe M (2001) Characterization of a FLORICAULA/ LEAFY homologue of Gnetum parvifolium and its implications for the evolution of reproductive organs in seed plants. Int J Plant Sci 162:1199-1209

Shindo C, Aranzana MJ, Lister C, Baxter C, Nicholls C, Nordborg M, Dean C (2005) Role of FRIGIDA and FLOWERING LOCUS $\mathrm{C}$ in determining variation in flowering time of Arabidopsis. Plant Physiol 138:1163-1173

Simonini S, Roig-Villanova I, Gregis V, Colombo B, Colombo L, Kater MM (2012) Basic pentacysteine proteins mediate MADS domain complex binding to the DNA for tissue-specific expression of target genes in Arabidopsis. Plant Cell 24:4163-4172 
Slotte T, Huang H, Lascoux M, Ceplitis A (2008) Polyploid speciation did not confer instant reproductive isolation in Capsella (Brassicaceae). Mol Biol Evol 25:1472-1481

Smaczniak C, Immink RG, Angenent GC, Kaufmann K (2012a) Developmental and evolutionary diversity of plant MADS-domain factors: insights from recent studies. Development 139:3081-3098

Smaczniak C, Immink RG, Muino JM, Blanvillain R, Busscher M, Busscher-Lange J, Dinh QD, Liu S, Westphal AH, Boeren S, Parcy F, Xu L, Carles CC, Angenent GC, Kaufmann K (2012b) Characterization of MADS-domain transcription factor complexes in Arabidopsis flower development. Proc Natl Acad Sci USA 109:1560-1565

Smeekens S, Ma J, Hanson J, Rolland F (2010) Sugar signals and molecular networks controlling plant growth. Curr Opin Plant Biol 13:274-279

Smith HM, Ung N, Lal S, Courtier J (2011) Specification of reproductive meristems requires the combined function of SHOOT MERISTEMLESS and floral integrators FLOWERING LOCUS T and FD during Arabidopsis inflorescence development. J Exp Bot 62:583-593

Sommer H, Beltran JP, Huijser P, Pape H, Lonnig WE, Saedler H, Schwarz-Sommer Z (1990) Deficiens, a homeotic gene involved in the control of flower morphogenesis in Antirrhinum majus: the protein shows homology to transcription factors. EMBO J 9:605-613

Song J, Angel A, Howard M, Dean C (2012a) Vernalization—a cold-induced epigenetic switch. J Cell Sci 125:3723-3731

Song Y, Gao Z, Luan W (2012b) Interaction between temperature and photoperiod. Sci China Life Sci 55:241-249

Song YH, Smith RW, To BJ, Millar AJ, Imaizumi T (2012c) FKF1 conveys timing information for CONSTANS stabilization in photoperiodic flowering. Science 336:1045-1049

Song XM, Huang ZN, Duan WK, Ren J, Liu TK, Li Y, Hou XL (2014) Genome-wide analysis of the bHLH transcription factor family in Chinese cabbage (Brassica rapa ssp. pekinensis). Mol Genet Genomics 289:77-91

Srikanth A, Schmid M (2011) Regulation of flowering time: all roads lead to Rome. Cell Mol Life Sci 68:2013-2037

Steffen JG, Kang IH, Portereiko MF, Lloyd A, Drews GN (2008) AGL61 interacts with AGL80 and is required for central cell development in Arabidopsis. Plant Physiol 148:259-268

Sung S, Amasino RM (2004a) Vernalization and epigenetics: how plants remember winter. Curr Opin Plant Biol 7:4-10

Sung S, Amasino RM (2004b) Vernalization in Arabidopsis thaliana is mediated by the PHD finger protein VIN3. Nature 427:159-164

Sung S, Schmitz RJ, Amasino RM (2006) A PHD finger protein involved in both the vernalization and photoperiod pathways in Arabidopsis. Genes Dev 20:3244-3248

Swiezewski S, Liu F, Magusin A, Dean C (2009) Cold-induced silencing by long antisense transcripts of an Arabidopsis Polycomb target. Nature 462:799-802

Tadege M, Sheldon CC, Helliwell CA, Stoutjesdijk P, Dennis ES, Peacock WJ (2001) Control of flowering time by FLC orthologues in Brassica napus. Plant J 28:545-553

Tanabe Y, Hasebe M, Sekimoto H, Nishiyama T, Kitani M, Henschel K, Munster T, Theissen G, Nozaki H, Ito M (2005) Characterization of MADS-box genes in charophycean green algae and its implication for the evolution of MADS-box genes. Proc Natl Acad Sci USA 102:2436-2441

Tanahashi T, Sumikawa N, Kato M, Hasebe M (2005) Diversification of gene function: homologs of the floral regulator FLO/LFY control the first zygotic cell division in the moss Physcomitrella patens. Development 132:1727-1736

Theissen G (2001) Development of floral organ identity: stories from the MADS house. Curr Opin Plant Biol 4:75-85

Theissen G, Melzer R (2007a) Combinatorial control of floral organ identity by MADS-domain transcription factors. In: Annual plant reviews, vol 29: regulation of transcription in plants. Blackwell, Oxford, pp 253-265 
Theissen G, Melzer R (2007b) Molecular mechanisms underlying origin and diversification of the angiosperm flower. Ann Bot 100:603-619

Theissen G, Saedler H (2001) Plant biology. Floral quartets. Nature 409:469-471

Theissen G, Becker A, Di Rosa A, Kanno A, Kim JT, Munster T, Winter KU, Saedler H (2000) A short history of MADS-box genes in plants. Plant Mol Biol 42:115-149

Trevaskis B, Bagnall DJ, Ellis MH, Peacock WJ, Dennis ES (2003) MADS box genes control vernalization-induced flowering in cereals. Proc Natl Acad Sci USA 100:13099-13104

Trevaskis B, Hemming MN, Dennis ES, Peacock WJ (2007) The molecular basis of vernalizationinduced flowering in cereals. Trends Plant Sci 12:352-357

Tsai AYL, Gazzarrini S (2014) Trehalose-6-phosphate and SnRK1 kinases in plant development and signalling: the emerging picture. Front Plant Sci 5:119. doi:10.3389/fpls.2014.00119

Turck F, Fornara F, Coupland G (2008) Regulation and identity of florigen: FLOWERING LOCUS T moves center stage. Annu Rev Plant Biol 59:573-594

Valverde F (2011) CONSTANS and the evolutionary origin of photoperiodic timing of flowering. J Exp Bot 62:2453-2463

Valverde F, Mouradov A, Soppe W, Ravenscroft D, Samach A, Coupland G (2004) Photoreceptor regulation of CONSTANS protein in photoperiodic flowering. Science 303:1003-1006

Valverde F, Ortega JM, Losada M, Serrano A (2005) Sugar-mediated transcriptional regulation of the Gap gene system and concerted photosystem II functional modulation in the microalga Scenedesmus vacuolatus. Planta 221:937-952

van Mourik S, van Dijk A, de Gee M, Immink R, Kaufmann K, Angenent G, van Ham R, Molenaar $\mathrm{J}$ (2010) Continuous-time modeling of cell fate determination in Arabidopsis flowers. BMC Syst Biol 4:101

Vandenbussche M, Zethof J, Souer E, Koes R, Tornielli GB, Pezzotti M, Ferrario S, Angenent GC, Gerats T (2003) Toward the analysis of the petunia MADS box gene family by reverse and forward transposon insertion mutagenesis approaches: B, C, and D floral organ identity functions require SEPALLATA-like MADS box genes in petunia. Plant Cell 15:2680-2693

Verhage L, Angenent GC, Immink RG (2014) Research on floral timing by ambient temperature comes into blossom. Trends Plant Sci 9:583-591

Wagner D, Sablowski RW, Meyerowitz EM (1999) Transcriptional activation of APETALA1 by LEAFY. Science 285:582-584

Wahl V, Ponnu J, Schlereth A, Arrivault S, Langenecker T, Franke A, Feil R, Lunn JE, Stitt M, Schmid M (2013) Regulation of flowering by trehalose-6-phosphate signaling in Arabidopsis thaliana. Science 339:704-707

Wang R, Farrona S, Vincent C, Joecker A, Schoof H, Turck F, Alonso-Blanco C, Coupland G, Albani MC (2009) PEP1 regulates perennial flowering in Arabis alpina. Nature 459:423-427

Wang H, Zhang Z, Li H, Zhao X, Liu X, Ortiz M, Lin C, Liu B (2013) CONSTANS-LIKE 7 regulates branching and shade avoidance response in Arabidopsis. J Exp Bot 64:1017-1024

Weigel D (1995) The APETALA2 domain is related to a novel type of DNA binding domain. Plant Cell 7:388-389

Weigel D, Nilsson O (1995) A developmental switch sufficient for flower initiation in diverse plants. Nature 377:495-500

Weigel D, Alvarez J, Smyth DR, Yanofsky MF, Meyerowitz EM (1992) LEAFY controls floral meristem identity in Arabidopsis. Cell 69:843-859

Wellmer F, Graciet E, Riechmann JL (2014) Specification of floral organs in Arabidopsis. J Exp Bot 65:1-9

Werner JD, Borevitz JO, Warthmann N, Trainer GT, Ecker JR, Chory J, Weigel D (2005) Quantitative trait locus mapping and DNA array hybridization identify an FLM deletion as a cause for natural flowering-time variation. Proc Natl Acad Sci USA 102:2460-2465

Westerman JM, Lawrence MJ (1970) Genotype-environment interaction and developmental regulation in Arabidopsis thaliana. I. Inbred lines; description. Heredity 25:18 
Wigge PA, Kim MC, Jaeger KE, Busch W, Schmid M, Lohmann JU, Weigel D (2005) Integration of spatial and temporal information during floral induction in Arabidopsis. Science 309:1056-1059

Wu L, Birch RG (2010) Physiological basis for enhanced sucrose accumulation in an engineered sugarcane cell line. Funct Plant Biol 37:1161-1174

Wu G, Poethig RS (2006) Temporal regulation of shoot development in Arabidopsis thaliana by miR156 and its target SPL3. Development 133:3539-3547

Wynne J, Treisman R (1992) SRF and MCM1 have related but distinct DNA binding specificities. Nucleic Acids Res 20:3297-3303

Xiao J, Xu S, Li C, Xu Y, Xing L, Niu Y, Huan Q, Tang Y, Zhao C, Wagner D et al (2014) OGlcNAc-mediated interaction between VER2 and TaGRP2 elicits TaVRN1 mRNA accumulation during vernalization in winter wheat. Nat Commun 5:4572

Xue W, Xing Y, Weng X, Zhao Y, Tang W, Wang L, Zhou H, Yu S, Xu C, Li X, Zhang Q (2008) Natural variation in Ghd7 is an important regulator of heading date and yield potential in rice. Nat Genet 40:761-767

Yamaguchi A, Wu MF, Yang L, Wu G, Poethig RS, Wagner D (2009) The microRNA-regulated SBP-Box transcription factor SPL3 is a direct upstream activator of LEAFY, FRUITFULL, and APETALA1. Dev Cell 17:268-278

Yan L, Loukoianov A, Tranquilli G, Helguera M, Fahima T, Dubcovsky J (2003) Positional cloning of the wheat vernalization gene VRN1. Proc Natl Acad Sci USA 100:6263-6268

Yan L, Loukoianov A, Blechl A, Tranquilli G, Ramakrishna W, SanMiguel P, Bennetzen JL, Echenique V, Dubcovsky J (2004) The wheat VRN2 gene is a flowering repressor downregulated by vernalization. Science 303:1640-1644

Yan L, Fu D, Li C, Blechl A, Tranquilli G, Bonafede M, Sanchez A, Valarik M, Yasuda S, Dubcovsky J (2006) The wheat and barley vernalization gene VRN3 is an orthologue of FT. Proc Natl Acad Sci USA 103:19581-19586

Yang J, Yang MF, Zhang WP, Chen F, Shen SH (2011) A putative flowering-time-related Dof transcription factor gene, JcDof3, is controlled by the circadian clock in Jatropha curcas. Plant Sci 181:667-674

Yano M, Katayose Y, Ashikari M, Yamanouchi U, Monna L, Fuse T, Baba T, Yamamoto K, Umehara Y, Nagamura Y, Sasaki T (2000) Hd1, a major photoperiod sensitivity quantitative trait locus in rice, is closely related to the Arabidopsis flowering time gene CONSTANS. Plant Cell 12:2473-2484

Yanofsky MF, Ma H, Bowman JL, Drews GN, Feldmann KA, Meyerowitz EM (1990) The protein encoded by the Arabidopsis homeotic gene agamous resembles transcription factors. Nature 346:35-39

Zhang B, Pan X, Cannon CH, Cobb GP, Anderson TA (2006) Conservation and divergence of plant microRNA genes. Plant J 46:243-259

Zhang Y, Primavesi LF, Jhurreea D, Andraloja PC, Mitchell RA, Powers SJ, Schluepmann H, Delatte T, Wingler A, Paul MJ (2009) Inhibition of SNF1-related protein kinase 1 and regulation of metabolic pathway by trehalose. Plant Physiol 149:1860-1871

Zhou L, Jang JC, Jones TL, Sheen J (1998) Glucose and ethylene signal transduction crosstalk revealed by an Arabidopsis glucose-insensitive mutant. Proc Natl Acad Sci USA 95:10294-10299 